\title{
The stem loop 2 motif is a site of vulnerability for SARS-CoV-2
}

(Valeria Lulla ${ }^{1, * *}$, Michal P. Wandel ${ }^{2}$, Katarzyna J. Bandyra ${ }^{3}$, Rachel Ulferts ${ }^{4}$, Mary $\mathrm{Wu}^{4}$, Tom Dendooven ${ }^{3}$, Xiaofei Yang $\left.{ }^{5}\right)^{*}$, Nicole Doyle ${ }^{6}$, Stephanie Oerum ${ }^{7}$, Rupert Beale ${ }^{4}$, Sara M. O’Rourke $^{8}$, Felix Randow ${ }^{2}$, Helena J. Maier ${ }^{6}$, [William Scott ${ }^{8}$, Yiliang Ding ${ }^{5}$, Andrew E. Firth $^{1}$, Kotryna Bloznelyte ${ }^{3}$, Ben F. Luisi $\left.{ }^{3}\right]^{* *}$

*These joint-first authors made complementary and equivalent contributions

**To whom correspondence may be addressed

${ }^{1}$ Department of Pathology, Division of Virology, University of Cambridge, Lab Block Level 5, Addenbrookes Hospital, Hills Road, Cambridge CB2 0QQ, U.K.

${ }^{2}$ MRC Laboratory of Molecular Biology, Francis Crick Avenue, Cambridge, CB2 0QH, U.K.

${ }^{3}$ Department of Biochemistry, University of Cambridge, Tennis Court Road, Cambridge CB2 1GA, U.K.

${ }^{4}$ The Francis Crick Institute, 1 Midland Road, London, NW1 1AT, U.K.

${ }^{5}$ Department of Cell and Developmental Biology, John Innes Centre, Norwich Research Park, Norwich, NR4 7UH, U.K.

${ }^{6}$ Pirbright Institute, Ash Road, Pirbright, Woking, GU24 ONF, U.K.

${ }^{7}$ CNRS-Université Paris Diderot, Institut de Biologie Physico-Chimique, 13 rue Pierre et Marie Curie, 75005 Paris, France

${ }^{8}$ University of California at Santa Cruz, Santa Cruz California, 95064, U.S.A.

Summary:

RNA structural elements occur in numerous single stranded (+)-sense RNA viruses. The stemloop 2 motif ( $2 \mathrm{~m})$ is one such element with an unusually high degree of sequence conservation, being found in the $3^{\prime}$ UTR in the genomes of many astroviruses, some picornaviruses and noroviruses, and a variety of coronaviruses, including SARS-CoV and SARS-CoV-2. The evolutionary conservation and its occurrence in all viral subgenomic transcripts implicates a key role of $\mathrm{s} 2 \mathrm{~m}$ in the viral infection cycle. Our findings indicate that the element, while stably folded, can nonetheless be invaded and remodelled spontaneously by antisense oligonucleotides (ASOs) that initiate pairing in exposed loops and trigger efficient sequence-specific RNA cleavage in reporter assays. ASOs also act to inhibit replication in an astrovirus replicon model system in a sequence-specific, dose-dependent manner and inhibit SARS-CoV-2 infection in cell culture. Our results thus permit us to suggest that the $\mathrm{s} 2 \mathrm{~m}$ element is a site of vulnerability readily targeted by ASOs, which show promise as anti-viral agents.

Keywords: s2m, positive-sense RNA virus, coronavirus, astrovirus, gapmer, LNA, therapeutic oligonucleotides, SARS-CoV-2 


\section{INTRODUCTION}

SARS-CoV-2 is a highly infectious virus and the causative agent of the ongoing COVID-19 pandemic. Given the continued rise in cases worldwide, the significant mortality rate and the challenges in predicting the severity of illness in infected individuals (Messner et al., 2020), there is a pressing need for efficacious antiviral therapies (Koirala et al., 2020; Krammer, 2020; https://www.who.int/emergencies/diseases/ /novel-coronavirus-2019). Moreover, the potential for further outbreaks of infections by emerging pathogenic coronaviruses (Menachery et al, 2015; Akula and McCubrey, 2020) places importance on improving fundamental understanding of coronavirus biology, as well as exploring novel therapeutics to build capability for a rapid response to the next zoonotic jump.

Like other positive-sense (+) single-stranded (ss) RNA viruses, replication of SARS-CoV-2 is orchestrated by virus-encoded enzymes inside infected host cells. The $30 \mathrm{~kb}$ long SARS-CoV2 genomic RNA and the subgenomic mRNA transcripts all contain a common 5'-leader sequence and a common 3' UTR, which harbour several conserved structural elements, including the stem-loop 2 motif (s2m) (Fig. 1A and B) (Rangan et al., 2020; Kim et al., 2020). The $\mathrm{s} 2 \mathrm{~m}$, originally identified in astroviruses (Jonassen et al., 1998), is a highly conserved RNA sequence element, present within the 3' UTR in the genomes of many astroviruses, some picornaviruses and noroviruses, and a variety of coronaviruses, including members of the subgenus Sarbecovirus, which includes SARS-CoV and SARS-CoV-2 viruses (Tengs et al., 2013, Tengs et al., 2016), and Merbecovirus, which includes MERS (Frey et al, 2014), the causative agents of three recent severe human pathogenic outbreaks. The SARS-CoV and SARS-CoV-2 s2m sequences are nearly identical, with only 2 point nucleotide divergence (Fig. 1A), in contrast to the overall $20 \%$ genome-wide sequence difference (Kim et al., 2020). The $\mathrm{s} 2 \mathrm{~m}$ sequence is also highly conserved in the clinical isolates from patients that have tested positive for SARS-CoV-2 during the current pandemic, although with a few isolated exceptions (GSAID database https://www.gisaid.org; UCSC genome browser; Vahed et al.,2020; Yeh and Contreras, 2020). The high degree of $\mathrm{s} 2 \mathrm{~m}$ sequence conservation is likely to be a direct consequence of a requirement to sustain an elaborate and conserved three-dimensional structure. Indeed, an earlier study of the SARS-CoV s2m element revealed a stable stem loop with a few exposed bases (Fig. 1B) in a $2.7 \AA$ resolution crystal structure (Robertson et al., 2005). Several more recent studies probed RNA accessibility and mapped RNA-RNA interactions of the $(+)$ sense SARS-CoV-2 viral species inside the host cell, confirming that the s2m stem-loop structure folds in vivo as well (Huston, 2020; Ziv et al., 2020).

Because of the apparent high degree of selective pressure to maintain this specific sequence and its structure, the $\mathrm{s} 2 \mathrm{~m}$ is a promising target for potential antiviral agents, with reduced likelihood of evolving mutations that would lead to resistance. Any agents targeting the $\mathrm{s} 2 \mathrm{~m}$ element would also have the advantage of acting against a large number of virus RNA species, due to the presence of the element in all $(+)$-sense virus RNAs, including both the full-length genome and the subgenomic mRNAs. In order to test the accessibility of the s $2 \mathrm{~m}$ element to potential nucleic acid-based therapeutics, we designed a panel of antisense oligonucleotides (ASOs). These oligonucleotides have proven therapeutic potential against viruses and have been undergoing active development for more than a decade (Bennett, 2019). Third-generation ASOs include locked nucleic acids (LNAs), in which a bicyclic linkage at the furanose constrains the conformational freedom of the nucleotide (Singh et al., 1998). LNAs provide high affinity base-pairing to complementary RNA and DNA targets, as well as resistance to nuclease attack (Hagedorn et al., 2018). A version of LNA ASOs known as 'gapmers' consists of LNA bases flanking a central DNA sequence (Wahlenstedt et al, 2000). In this design, LNA 
bases confer resistance to nucleases and provide high-affinity base-pairing to target RNA, while the central DNA region, once base-paired to RNA, recruits ribonuclease $H(R N a s e H)$, which acts to cleave the RNA in the RNA-DNA duplex. In this process, the DNA is not digested and thus the gapmer remains intact and free to bind further RNA molecules. Gapmers have already been successfully used in clinical trials to silence target transcripts (Bonneau et al., 2019).

In this report, we describe the design and testing of several LNA ASOs (gapmers) against the highly conserved structured s2m element from the 3' UTR of SARS-CoV-2. We found by chemical probing of the RNA target element that despite the high degree of structural compactness, ASOs were successfully disrupting the s2m structure. Furthermore, gapmers were capable of inducing sequence-specific RNA cleavage in vitro and in multiple independent cell-based platforms, including a human reporter system, an astrovirus replicon assay, and direct inhibition of SARS-CoV-2 replication in infected cells. Our results support targeting of the $\mathrm{s} 2 \mathrm{~m}$ element and other conserved structures with predicted exposed loops in the viral genomes by ASOs. In addition, the particular gapmer designs described here may offer suitable lead compounds for further development as antiviral therapeutics to treat COVID-19 and other diseases caused by RNA viruses possessing the s2m element in their genomes.

\section{RESULTS}

\section{Model for the s2m element in the context of the SARS-CoV-2 3' UTR}

Given the high sequence similarity between the s2m elements in the SARS-CoV-2 and SARSCoV genomes (Fig. 1A), the corresponding structures are expected to show high similarity as well. The crystal structure of the SARS-CoV s2m reveals a stem loop with a small pocket that can accommodate cations (Fig. 1B; Robertson et al., 2005) and suggests a similar fold for the SARS-CoV-2 s2m. To test this experimentally, we probed the structure of the SARS-CoV-2 s2m element within the genomic 3' UTR using SHAPE (Selective 2'-Hydroxyl Acylation

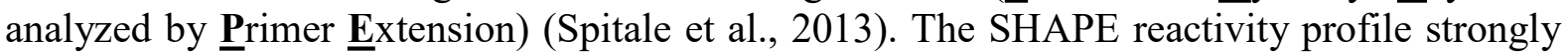
agrees with the crystal structure of the SARS-CoV s2m element (Fig. 1C). For instance, high SHAPE reactivities were found at the loop region (G71-A75), indicating strong possibility of a single-stranded nature, while low SHAPE reactivities were found for nucleotides predicted to be base-paired, such as nucleotides 54-58, and nucleotides 90-94. We performed further SHAPE probing on an extended version of the 3' UTR RNA ("extended 3' UTR") that additionally includes ORF10 and the region immediately upstream from it (ORF10 may not be protein coding; Taiaroa et al., 2020; Jungreis et al., 2020) (Fig. S1 and Table 1). We found a high degree of consistency between the SHAPE profiles for the s2m element in the extended and non-extended constructs (Pearson correlation coefficient PCC $=0.996$, Fig. S1B and S1C), indicating that the s2m element in the $3^{\prime}$ UTR is stably folded and is unlikely to be affected by flanking regions such as ORF10. Stable structural unit formation by $\mathrm{s} 2 \mathrm{~m}$, maintained within an extended surrounding sequence, has also been observed in a recent NMR and DMS chemical probing study (Wacker et al., 2020), with experimental data agreeing with the s2m secondary structure proposed here (Fig. 1C). Further support for our findings comes from recent wholegenome studies of the SARS-CoV-2 RNA structure, which show good agreement between SHAPE reactivity and in silico predictions and identify s2m stem loop in this context (Huston, 2020; Manfredonia et al, 2020).

To further investigate potential structures formed by the viral 3' UTR as a whole, we used cryoelectron microscopy. Imaging this RNA fragment mainly yielded elongated shapes resembling 
thick rope, up to $500 \AA \AA$ in length (Fig. 1D). A subset of the ropey particles were less extended, measuring around $300 \AA$, which is about half the length expected for an elongated polymer, implying that the RNA there is semi-compact. These particles were subjected to computational 2D/3D averaging in an attempt to reveal underlying shared structural features (Fig 1E and F). However, none could be clearly identified, suggesting that the 3' UTR RNA does not fold into a well-defined structure, at least in vitro.

Our cryo-electron microscopy observations give support to earlier in vivo studies, where cells infected with SARS-CoV-2 virus were probed by cryo-electron tomography (Klein et al., 2020). Both the tomography study and our single-particle imaging reveal small, high-contrast features at the periphery of the RNA particles, which might represent views down the long axis of some duplex RNA regions (Fig. 1D, red arrows).

Overall, based on the prediction from the SARS-CoV s2m RNA crystal structure and our SHAPE probing results, we conclude that the s2m element in the $3^{\prime}$ UTR of SARS-CoV-2 RNA folds into a stem-loop structure, which may be highly conserved among coronaviruses. This is in contrast to the entire 3' UTR as a whole, for which we do not observe any welldefined global structure.

\section{Design of LNA ASO gapmers against the s2m element; assessment of binding and activity in vitro}

Although the highly conserved nature of the s2m element makes it an attractive target for therapies based on ASOs, the structured nature of the target may potentially interfere with ASO-target base-pairing. To facilitate gapmer-induced disruption of the native s2m structure, we designed gapmers so that the high-affinity LNA bases would pair with the RNA bases predicted to be exposed in the s2m element (Fig. 2 and Table 3). This pairing should facilitate initial gapmer-target interaction, hypothetically leading to unfolding of the s $2 \mathrm{~m}$ element as the rest of the gapmer base-pairs with the complementary target nucleotides.

We designed a panel of gapmers and tested their ability to direct RNase $\mathrm{H}$ cleavage in vitro, using s2m RNA as the substrate for the purified enzyme (Fig. 2A and D). Gapmers 1-3 were designed to have higher affinity for target RNA than gapmers 4-6, as indicated by respective predicted melting temperatures (schematic top panel, Fig. 2 and Table 3). The presence of the sequence-specific gapmers 1-6 in the digestion reactions led to clear degradation of target RNA, regardless of their predicted melting temperature bracket, whereas non-sequencespecific control gapmer with scrambled sequence failed to have an effect ("scr", Fig. 2D). The degradation was very efficient even for 2:1 s2m:gapmer molar ratio, indicating that gapmers can be recycled and can direct multiple turnover of substrates by RNase H. Gapmers 1-6 also drove cleavage of the whole 3' UTR (Fig. 2B and E) and of the "extended 3' UTR" construct that additionally includes ORF10 and the region immediately upstream of it (Fig. $2 \mathrm{~F}$ ), indicating that the target $\mathrm{s} 2 \mathrm{~m}$ sequence is successfully recognised and is accessible for gapmer base-pairing in its native sequence context. The observation that both the higher-affinity gapmers 1-3 (Fig. 2A and B) and the lower-affinity gapmers 4-6 (Fig. 2 D, E and F) were able to direct $\mathrm{RNase} \mathrm{H}$ cleavage of the $\mathrm{s} 2 \mathrm{~m}$ element indicates that a range of gapmer-target affinities are compatible with successful target degradation of the highly structured s $2 \mathrm{~m}$ sequence. This flexibility in gapmer design is particularly important as higher affinity gapmers may be expected to have more off-target interactions in cells, which may be reduced in lower-affinity variants. 
199 Additionally, we designed and tested gapmers targeting a single-stranded conserved region in

200 SARS-CoV-2, at position 1359-1374 relative to the NC_045512.2 virus reference genome

201 ("ss3"; Rangan et al., 2020) and tested alternative gapmer backbone chemistries with these.

202 Gapmers designated "all" and "some" have the same sequence and base composition, but

203 different polymer backbones (Table 3). The entire backbone of gapmer "all" contains

204 phosphorothioate modifications, as is also the case in gapmers 1-6; it is a well-established modification conferring some nuclease resistance to oligonucleotides (Kumar et al., 1998; Eckstein, 2000). The backbone in gapmer "some", however, is mixed; DNA bases are linked by phosphodiester backbone, whereas LNA bases are linked by phosphorothioate backbone.

In vitro digestion experiments (Fig. $2 \mathrm{C}$ ) indicate that both chemistries are compatible with

210 RNase H recruitment and target RNA degradation and also suggest general applicability of gapmer-induced degradation of viral RNA sequences. Gapmer "some" appears to have higher binding affinity for the "ss3" target, judging from the presence of an extra band at the top of the gel in Fig. 2C, which likely corresponds to a gapmer-target dimer. This is consistent with expectation, as phosphorothioate modifications are known to reduce target affinity (Grünweller et al., 2003), so gapmer "all" would be expected to show weaker binding than gapmer "some". On the other hand, gapmer "all" generates a higher amount of cleaved product (Fig. 2C), which supports our choice of phosphorothioate backbone throughout gapmers 1-6.

\section{s2m structure is successfully remodelled by LNA gapmers}

To test whether gapmers have any effect on the s2m structure, we performed SHAPE probing of SARS-CoV-2 3' UTR in the presence of gapmers 1, 2 and 3 targeting s2m and gapmer "all" as a non-specific control. Since SHAPE probing detects the accessibility of nucleotides (Spitale et al., 2013), it is capable of revealing both intra- and inter-molecular RNA base-pairing interactions.

In the presence of gapmer 1 and gapmer 2, SHAPE reactivity profiles strongly decreased in the regions targeted by the gapmers, indicating inter-molecular interactions formed between gapmers and their target sequences (Fig. 3A-D). In contrast, SHAPE reactivities strongly increased in the regions that were originally base-paired with the gapmer-target regions and in their flanking regions, indicating they were more single-stranded in the presence of gapmers, consistent with expectation.

In the presence of gapmer 3, which targets the single-stranded loop region within s2m, SHAPE reactivity profile showed a strong decrease in this region (Fig. 3E and F), indicating successful targeting by gapmer. We also found that this inter-molecular interaction between gapmer 3 and the loop region led to increased SHAPE reactivities downstream of the loop region. This suggests that inter-molecular interactions between gapmers and target regions could also remodel the folding status of flanking regions.

Notably, the observed changes in SHAPE reactivity were dependent on the concentration of gapmers and were not detected in the presence of a control gapmer (gapmer "all") which is not able to target the s $2 \mathrm{~m}$ element (Fig. $3 \mathrm{G}$ and $\mathrm{H}$ ). Taken together, our results validate the design of gapmers in targeting the $\mathrm{s} 2 \mathrm{~m}$ element and highlight the effect of gapmers in remodelling s2m structure.

\section{s2m acts to direct gapmer-induced reporter gene silencing in human cells}


To investigate if gapmers against the s2m element could drive target RNA silencing in human cells, we set up a tissue culture-based reporter system. We generated lung-derived A549 and HeLa cell reporter lines carrying stably integrated GFP genes that encode either the wild type $\mathrm{s} 2 \mathrm{~m}$ element or a scrambled control sequence in the $3^{\prime}$ UTR (Fig. S2A and B). Transfection with gapmers against $\mathrm{s} 2 \mathrm{~m}$ reduced GFP fluorescence levels in the two $\mathrm{s} 2 \mathrm{~m}$-containing cell lines for both the higher-affinity gapmers 1-3 and the lower-affinity gapmers 5-6 (Fig. 4A and B). Gapmer 4, the shortest of the tested gapmers and containing only six DNA nucleotides (Table 3), had no effect (Fig. 4A and B); this may reflect difficulties in recruiting human RNase $\mathrm{H}$ in vivo to this length of RNA-DNA duplex (Kurreck et al., 2002). Non-specific control gapmers did not affect GFP fluorescence levels, nor did treatment with s2m-specific gapmers of control cell lines in which the sequence of the $\mathrm{s} 2 \mathrm{~m}$ element was scrambled (Fig. S3A and B). These results indicate that the silencing effect relies on sequence-specific

261

262

263

264

265

266 gapmer-target interaction. Overall, the results show that gapmers against the $\mathrm{s} 2 \mathrm{~m}$ element have the potential to silence gene expression from mRNAs containing $\mathrm{s} 2 \mathrm{~m}$ in their $3^{\prime} \mathrm{UTR}$ sequences, which is the case for SARS-CoV-2 mRNAs.

Our experimental method also functioned to test the hypothesis that the $\mathrm{s} 2 \mathrm{~m}$ is a posttranscriptional response element. We used the GFP reporter cell lines to compare fluorescence levels between the GFP-s2m and GFP-scrambled cells. No difference was observed, indicating that the $\mathrm{s} 2 \mathrm{~m}$ element itself does not affect fluorescent protein production (Fig. S2C) suggesting that it does not act as an independent element in cis in translation of viral mRNAs.

270

271

272

273

274

275

276

277

\section{LNA gapmers against $\mathbf{s} 2 \mathrm{~m}$ inhibit replication in an astrovirus replicon model system in human cells}

To investigate the effects of s2m-targeting LNA gapmers on viral replication, initially we employed an astrovirus replicon system. Many $(+)$ ssRNA viruses share a similar repertoire of genetic elements required for the replication of viral RNA, and this is true in the case of coronaviruses and astroviruses. Despite large differences in genome size, coronaviruses and astroviruses possess a similar modular organization, including the order of non-structural and structural genes, a frameshift signal to access the RNA-dependent RNA polymerase (RdRp) open reading frame, and production of 3'-coterminal subgenomic mRNAs for structural and accessory protein expression. Like coronaviruses, many astroviruses - including human astrovirus 1 (HAstV1) - contain an s2m element in the 3' UTR of their genomes (Fig. 5A). We have recently developed a robust HAstV1-based replicon system (Fig. 5A, lower panel), which permits the evaluation of RNA replication in multiple cell types (Lulla and Firth, 2020). The small astroviral genome size $(\sim 7 \mathrm{~kb})$ compared to coronaviruses $(\sim 30 \mathrm{~kb})$, allows for rapid manipulation of sequences for anti-viral testing in a less restrictive environment than that required to manipulate SARS-CoV-2.

Building on promising results in a cell-based reporter system, we used the astrovirus system to test gapmer efficacy in the context of virus-like replication, where replicative intermediates are generally physically occluded within host membrane derived vesicles, as is also the case in bona fide virus infection. We generated chimeric astrovirus replicons bearing the s $2 \mathrm{~m}$ elements from SARS-CoV or SARS-CoV-2 (Fig. 5B). Chimeric replicons recapitulated the replication properties of the wild-type astrovirus replicon (Fig. 5C), indicating that this system is suitable for testing gapmers against multiple $\mathrm{s} 2 \mathrm{~m}$ sequences. To rule out any potential cell-specific effects, all gapmers were tested in two human cell lines - Huh7.5.1 (Lulla and Firth, 2020) and HEK293T (optimised for this study). The replication of replicons bearing SARS-CoV-2 s2m sequences was efficiently inhibited by gapmers 1,2 , and 5, causing inhibition in the sub- 
nanomolar range, with a less pronounced effect found for gapmers 3, 4, and 6. The inhibition of non-specific control gapmers ("all" and "scr") was significantly below their compositionmatched counterparts, gapmers 1-3 and 4-6, respectively (Fig. 5D). The same gapmers were also tested against the SARS-CoV s2m in this system and found to be active, though with a lower potency (Fig. 5E). This could potentially be attributed to differences arising from C-G versus $\mathrm{C}-\mathrm{U}$ juxtaposition within the respective $\mathrm{s} 2 \mathrm{~m}$ elements (Fig. 5B), leading to changes in the s2m structure (Aldhumani et al., 2021), thus potentially affecting the s $2 \mathrm{~m}$ gapmer binding properties. Replication in the presence of sufficient concentrations of gapmers 1,2 or 5 dropped to the baseline level of the pO2RL-GNN mutant, which is completely deficient in replication due to a mutated RdRp active site (Fig. 5C).

To assess the cytotoxicity and potential off-target effects of the tested gapmers, we (i) performed a lactate dehydrogenase release-based cytotoxicity assay, and (ii) evaluated the efficiency of cap-dependent translation in the presence of the different gapmer concentrations. Consistent with previous work (Kaur et al., 2007), these assays showed no gapmer-induced cellular toxicity (Fig. S4A). Translation inhibition of $>50 \%$ was only observed at $500 \mathrm{nM}$ concentrations of gapmers 1, 2, 5 and 6 (Fig. S4B), which is at least 10-fold higher than the effective inhibition range for gapmers 1,2 and 5. Overall, these results suggest that gapmers targeting the $\mathrm{s} 2 \mathrm{~m}$ element can inhibit viral replication in the model replicon system in a dosedependent, sequence-specific manner without causing significant cell toxicity.

\section{SARS-CoV-2 infection is inhibited by LNA gapmers targeting s2m}

A high content screening (HCS) assay was developed to measure the effects of LNA gapmers on infection in Vero E6 cells infected with SARS-CoV-2. Figure 6A shows a graphical representation of the HCS assay workflow and an example representative microscopy image, with cells stained for $\mathrm{N}$ protein (488 nm signal). We tested gapmers 1-6, "all" and "scr" at 0.25 , 0.5 and $1 \mu \mathrm{M}$ concentrations, a no-gapmer control, and $10 \mu \mathrm{M}$ remdesivir treated cells as a positive control. Our results indicate that gapmers 2 and 5 inhibit infection in a dose-dependent manner, reducing virus replication (measured through $\mathrm{N}$ protein expression) to 10.4 and $6.9 \%$, respectively, of the non-treated control at $1 \mu \mathrm{M}$ concentration, with cell viability at $72 \%$ and $83 \%$, respectively. Furthermore, the inhibition levels are comparable to the $10 \mu \mathrm{M}$ remdesivir control in this assay (Fig. 6B). Gapmer 1, 3, and 6 have a less profound effect $(27 \%, 31 \%$, and $17 \%$ of non-treated control levels at $1 \mu \mathrm{M}$ ), whereas gapmer 4 shows the highest toxicity levels besides inhibition to $13 \%$ of the non-treated control. In strong agreement with the astrovirus replicon-based results (Fig. 5D), gapmers 2 and 5 demonstrate the most promising results in SARS-CoV-2 inhibition assays (Fig. 6B), suggesting the suitability of these two gapmers for therapeutic development. Consistent with our previous results on other cell lines (Fig. S4A), the gapmers show no cytotoxic effect on Vero E6 cells in the absence of transfection reagent $(<5 \%$, Fig. 6C), providing further confidence for potential therapeutic gymnotic delivery (Fazil et al., 2016). These results are consistent with the astrovirus replicon-based approach and indicate that gapmers may have sufficient access to their RNA target in infected cells and that gapmers against the conserved s $2 \mathrm{~m}$ element may act as a viable anti-viral agent, warranting their further exploration as therapeutics.

\section{DISCUSSION}

We have confirmed that the highly conserved structural element $\mathrm{s} 2 \mathrm{~m}$ in the $3^{\prime}$ UTR of SARSCoV-2 RNA is a site of vulnerability and a feasible candidate for ASO-based targeting by designing LNA-based gapmer ASOs effective against the $\mathrm{s} 2 \mathrm{~m}$ element in vitro and in vivo. We 
demonstrated physical gapmer-induced disruption of the RNA structure, consistent with successful gapmer-target base-pairing interactions, and RNase $\mathrm{H}$-induced target degradation in vitro. Furthermore, we have demonstrated that the $\mathrm{s} 2 \mathrm{~m}$ element can direct gapmer-induced silencing of gene expression in GFP reporter assays in human cells, likely relying on the demonstrated enzymatic activity of endogenous RNase $\mathrm{H}$ in the nucleus and the cytoplasm (Liang et al., 2017).

We extended the observation by testing the ability of $\mathrm{s} 2 \mathrm{~m}$-targeting gapmers to inhibit viral replication in an astrovirus-based replicon model system, a rapid functional assay that does not require access to higher containment level facilities. Viral replicon assays showed that gapmers against $\mathrm{s} 2 \mathrm{~m}$ inhibit viral replication in a sequence-specific, dose-dependent manner, down to sub-nanomolar range. These observations confirm that gapmers have significant potential as RNA replication inhibitors. Results from SARS-CoV-2 infection assays in cell culture with LNA gapmers targeting s $2 \mathrm{~m}$ are highly encouraging, with inhibition observed at the $0.25-1 \mu \mathrm{M}$ gapmer concentration range. Two of the tested gapmers, 2 and 5, provided consistent inhibition results in both systems without increased cellular toxicity.

It is worth noting that coronaviruses produce double membrane vesicles inside infected host cells, thought to conceal the viral double-stranded RNA replicative intermediate from cellular defences (Hagemeijer et al., 2012; Knoops et al., 2008). These vesicles have been proposed to be formed through virus-induced manipulations of the membrane of endoplasmic reticulum (Blanchard and Roingeard, 2015). This compartmentalization of the SARS-CoV-2 genome in membranous bodies within the host cell's cytoplasm (Klein et al., 2020) may reduce access of the ASOs to the s2m element or other viral genomic targets (although viral mRNAs, which all contain $\mathrm{s} 2 \mathrm{~m}$, should still be accessible). In this regard, it is useful to consider that LNA ASOs have been conjugated with tocopherol and cholesterol for membrane association in the past (Benizri et al., 2019; Nishina et al., 2015), which could increase ASO ability to find its target. Improved membrane association may also boost gapmer entry into target cells. The primary targets for the SARS-CoV-2 infection are the ACE2 receptor expressing airway cells, with the virus infection gradually decreasing from the proximal to distal respiratory tract (Hou et al., 2020). These cells might be amenable to aerosol delivery (Drevinek et al., 2020), enabling highly targeted therapeutic administration.

When considering $\mathrm{s} 2 \mathrm{~m}$ as a target for virus inhibition, it is also worth noting that while it is a remarkably stable genomic element, conserved across multiple groups of single-stranded $(+)$ sense RNA viruses, some mutations can arise over time. In the SARS-CoV-2 sequences from Covid-19 patient samples, some s2m polymorphisms have been detected at positions 15 and 31, predicted to destabilise the stem loop structure (Vahed et al, 2020; Yeh and Contreras, 2020). Using a combination of several gapmers together offers a potential strategy to guard against emerging resistance.

The results described here represent a promising start for further research into targeting conserved elements in single-stranded $(+)$ sense RNA viruses, and support development of gapmers and related ASOs against the $\mathrm{s} 2 \mathrm{~m}$ element in particular. In the case of the SARS-CoV2, our gapmer designs offer a strong starting point for further therapeutic development, which may include large scale optimisation and screening to maximise efficacy in cell culture and animal models, as well as chemical modifications for optimal delivery to target cells.

\section{ACKNOWLEDGEMENTS}


AEF and VL are supported by Wellcome Trust (106207) and European Research Council (646891) grants. KJB, TD, KB and BFL are supported by a Wellcome Trust Investigator Award (200873/Z/16/Z) and TD by an Astra-Zeneca Studentship. X.Y and Y.D. are supported by a European Commission Horizon 2020 European Research Council (ERC) Starting Grant (680324). HJM and ND are supported by BBSRC (BBS/E/I/00007031 and BBS/E/I/00007037) grants. All cryoEM grids were prepared and cryoEM data collected at the BIOCEM facility, Department of Biochemistry, University of Cambridge. We thank Dimitri Y. Chirgadze, Steve Hardwick and Lee Cooper for assistance with data collection at the CryoEM Facility. We thank David LV Bauer for critical help with facilitating gapmer tests in virus infection assays. We thank Laura McCoy for the CR3009 antibody expression plasmids and Svend Kjaer at the Structural Biology Service Technology Platform at the Francis Crick Institute for preparation of the antibody. We thank Henrik Oerum, Alex Borodavka, Chris Oubridge and Ulrich Desselberger for invaluable advice and helpful discussions. We thank Dingquan Yu and Zhichao Miao for help with sequence analysis. We thank the support staff in our institutions for their invaluable help throughout the pandemic lockdown period. We dedicate this manuscript to the memory of our colleague Chris Oubridge.

\section{REFERENCES}

Akula, S. M., \& McCubrey, J. A. (2020). Where are we with understanding of COVID19? Advances in Biological Regulation, 77, 100745.

https://doi.org/10.1016/j.jbior.2020.100745

Aldhumani, A.H., Hossain, M.I., Fairchild, E. A., Boesger, H., Marino, E.C., Myers, M., Hines, J.V. (2021). RNA sequence and ligand binding alter conformational profile of SARSCoV-2 stem loop II motif. Biochemical and Biophysical Research Communications, 545, 7580. https://doi.org/10.1016/j.bbrc.2021.01.013

Benizri, S., Gissot, A., Martin, A., Vialet, B., Grinstaff, M. W., \& Barthélémy, P. (2019).

Bioconjugated Oligonucleotides: Recent Developments and Therapeutic

Applications. Bioconjugate Chemistry, 30(2), 366-383.

https://doi.org/10.1021/acs.bioconjchem.8b00761

Bennett C. F. (2019). Therapeutic Antisense Oligonucleotides Are Coming of Age. Annual Review of Medicine, 70, 307-321. https://doi.org/10.1146/annurev-med-041217-010829

Blanchard, E., \& Roingeard, P. (2015). Virus-induced double-membrane vesicles. Cellular Microbiology, 17(1), 45-50. https://doi.org/10.1111/cmi.12372

Bonneau, E., Neveu, B., Kostantin, E., Tsongalis, G. J., \& De Guire, V. (2019). How close are miRNAs from clinical practice? A perspective on the diagnostic and therapeutic market. EJIFCC, 30(2), 114-127.

Drevinek, P., Pressler, T., Cipolli, M., De Boeck, K., Schwarz, C., Bouisset, F., Boff, M., Henig, N., Paquette-Lamontagne, N., Montgomery, S., Perquin, J., Tomkinson, N., den Hollander, W., \& Elborn, J. S. (2020). Antisense oligonucleotide eluforsen is safe and improves respiratory symptoms in F508DEL cystic fibrosis. Journal of Cystic Fibrosis, 19(1), 99-107. https://doi.org/10.1016/j.jcf.2019.05.014 
Eckstein F. (2000). Phosphorothioate oligodeoxynucleotides: what is their origin and what is unique about them? Antisense \& Nucleic Acid Drug Development, 10(2), 117-121. https://doi.org/10.1089/oli.1.2000.10.117

Fazil, M., Ong, S., Chalasani, M., Low, J.H., Kizhakeyil, A., Mamidi, A., Lim, C.F.H., Wright, G.D., Lakshminarayanan, R., Kelleher, D., Verma, N.K. (2016). GapmeR cellular internalization by macropinocytosis induces sequence-specific gene silencing in human primary T-cells. Science Reports, 6, 37721. https://doi.org/10.1038/srep37721

Frey, K. G., Redden, C. L., Bishop-Lilly, K. A., Johnson, R., Hensley, L. E., Raviprakash, K., Luke, T., Kochel, T., Mokashi, V. P., \& Defang, G. N. (2014). Full-genome sequence of human betacoronavirus 2c jordan-n3/2012 after serial passage in Mammalian cells. Genome Announcements, 2(3), e00324-14. https://doi.org/10.1128/genomeA.00324-14

Grünweller, A., Wyszko, E., Bieber, B., Jahnel, R., Erdmann, V. A., \& Kurreck, J. (2003). Comparison of different antisense strategies in mammalian cells using locked nucleic acids, 2'-O-methyl RNA, phosphorothioates and small interfering RNA. Nucleic Acids Research, 31(12), 3185-3193. https://doi.org/10.1093/nar/gkg409

Hagedorn, P. H., Persson, R., Funder, E. D., Albæk, N., Diemer, S. L., Hansen, D. J., Møller, M. R., Papargyri, N., Christiansen, H., Hansen, B. R., Hansen, H. F., Jensen, M. A., \& Koch, T. (2018). Locked nucleic acid: modality, diversity, and drug discovery. Drug Discovery Today, 23(1), 101-114. https://doi.org/10.1016/j.drudis.2017.09.018

Hagemeijer, M. C., Vonk, A. M., Monastyrska, I., Rottier, P. J., \& de Haan, C. A. (2012). Visualizing coronavirus RNA synthesis in time by using click chemistry. Journal of Virology, 86(10), 5808-5816. https://doi.org/10.1128/JVI.07207-11

Hou, Y. J., Okuda, K., Edwards, C. E., Martinez, D. R., Asakura, T., Dinnon, K. H., 3rd, Kato, T., Lee, R. E., Yount, B. L., Mascenik, T. M., Chen, G., Olivier, K. N., Ghio, A., Tse, L. V., Leist, S. R., Gralinski, L. E., Schäfer, A., Dang, H., Gilmore, R., Nakano, S., ... Baric, R. S. (2020). SARS-CoV-2 Reverse Genetics Reveals a Variable Infection Gradient in the Respiratory Tract. Cell, 182(2), 429-446.e14. https://doi.org/10.1016/j.cell.2020.05.042

Huston, N. C., Wan, H., Araujo Tavares, R. C., Wilen, C., \& Pyle, A. M. (2020). Comprehensive in-vivo secondary structure of the SARS-CoV-2 genome reveals novel regulatory motifs and mechanisms. bioRxiv, 2020.07.10.197079. https://doi.org/10.1101/2020.07.10.197079

Jungreis, I., Sealfon, R., \& Kellis, M. (2020). Sarbecovirus comparative genomics elucidates gene content of SARS-CoV-2 and functional impact of COVID-19 pandemic mutations. bioRxiv, 2020.06.02.130955. https://doi.org/10.1101/2020.06.02.130955

Kaur, H., Babu, B. R., \& Maiti, S. (2007). Perspectives on chemistry and therapeutic applications of Locked Nucleic Acid (LNA). Chemical Reviews, 107(11), 4672-4697. https://doi.org/10.1021/cr050266u

Kim, D., Lee, J. Y., Yang, J. S., Kim, J. W., Kim, V. N., \& Chang, H. (2020). The Architecture of SARS-CoV-2 Transcriptome. Cell, 181(4), 914-921.e10. https://doi.org/10.1016/j.cell.2020.04.011 
Klein, S., Cortese, M., Winter, S.L., Wachsmuth-Melm, M., Neufeldt, C.J., Cerikan, B., Stanifer, M.L., Boulant, S., Bartensclager, R. and Chlanda, P. (2020) SARS-CoV-2 structure and replication characterised by in situ cryo-electron tomography. bioRxiv 2020.06.23.167064; doi: https://doi.org/10.1101/2020.06.23.167064

Knoops, K., Kikkert, M., Worm, S. H., Zevenhoven-Dobbe, J. C., van der Meer, Y., Koster, A. J., Mommaas, A. M., \& Snijder, E. J. (2008). SARS-coronavirus replication is supported by a reticulovesicular network of modified endoplasmic reticulum. PLoS Biology, 6(9), e226. https://doi.org/10.1371/journal.pbio.0060226

Koirala, A., Joo, Y. J., Khatami, A., Chiu, C., \& Britton, P. N. (2020). Vaccines for COVID19: The current state of play. Paediatric Respiratory Reviews, S1526-0542(20)30095-6. Advance online publication. https://doi.org/10.1016/j.prrv.2020.06.010

Krammer, F. SARS-CoV-2 vaccines in development. Nature 586, 516-527 (2020). https://doi.org/10.1038/s41586-020-2798-3)

Kumar, R., Singh, S. K., Koshkin, A. A., Rajwanshi, V. K., Meldgaard, M., \& Wengel, J. (1998). The first analogues of LNA (locked nucleic acids): phosphorothioate-LNA and 2'thio-LNA. Bioorganic \& Medicinal Chemistry Letters, 8(16), 2219-2222. https://doi.org/10.1016/s0960-894x(98)00366-7

Kurreck, J., Wyszko, E., Gillen, C., \& Erdmann, V. A. (2002). Design of antisense oligonucleotides stabilized by locked nucleic acids. Nucleic Acids Research, 30(9), 19111918. https://doi.org/10.1093/nar/30.9.1911

Liang, X. H., Sun, H., Nichols, J. G., \& Crooke, S. T. (2017). RNase H1-Dependent Antisense Oligonucleotides Are Robustly Active in Directing RNA Cleavage in Both the Cytoplasm and the Nucleus. Molecular Therapy: the journal of the American Society of Gene Therapy, 25(9), 2075-2092. https://doi.org/10.1016/j.ymthe.2017.06.002 prediction. Methods (San Diego, Calif.), 52(2), 150-158. https://doi.org/10.1016/j.ymeth.2010.06.007

Lulla, V., \& Firth, A. E. (2020). A hidden gene in astroviruses encodes a viroporin. Nature communications, 11(1), 4070. https://doi.org/10.1038/s41467-020-17906-x

Manfredonia, I., Nithin, C., Ponce-Salvatierra, A., Ghosh, P., Wirecki, T. K., Marinus, T., Ogando, N. S., Snider, E. J., Martijn J. van Hemert, Janusz M. Bujnicki, Incarnato, D. (2020). Genome-wide mapping of therapeutically-relevant SARS-CoV-2 RNA structures. bioRxiv 2020.06.15.151647; doi: https://doi.org/10.1101/2020.06.15.151647

Menachery, V. D., Yount, B. L., Jr, Debbink, K., Agnihothram, S., Gralinski, L. E., Plante, J. A., Graham, R. L., Scobey, T., Ge, X. Y., Donaldson, E. F., Randell, S. H., Lanzavecchia, A., Marasco, W. A., Shi, Z. L., \& Baric, R. S. (2015). A SARS-like cluster of circulating bat coronaviruses shows potential for human emergence. Nature Medicine, 21(12), 1508-1513. 
548 Messner, C. B., Demichev, V., Wendisch, D., Michalick, L., White, M., Freiwald, A.,

549 Textoris-Taube, K., Vernardis, S. I., Egger, A. S., Kreidl, M., Ludwig, D., Kilian, C.,

550 Agostini, F., Zelezniak, A., Thibeault, C., Pfeiffer, M., Hippenstiel, S., Hocke, A., von Kalle,

551 C., Campbell, A., ... Ralser, M. (2020). Ultra-High-Throughput Clinical Proteomics Reveals

552 Classifiers of COVID-19 Infection. Cell Systems, 11(1), 11-24.e4.

553 https://doi.org/10.1016/j.cels.2020.05.012

Nishina, T., Numata, J., Nishina, K., Yoshida-Tanaka, K., Nitta, K., Piao, W., Iwata, R., Ito,

S., Kuwahara, H., Wada, T., Mizusawa, H., \& Yokota, T. (2015). Chimeric Antisense

Oligonucleotide Conjugated to $\alpha$-Tocopherol. Molecular Therapy. Nucleic acids, 4(1), e220. https://doi.org/10.1038/mtna.2014.72

559

560

Punjani, A., Rubinstein, J. L., Fleet, D. J., \& Brubaker, M. A. (2017). cryoSPARC:

561

562 algorithms for rapid unsupervised cryo-EM structure determination. Nature Methods, 14(3), 290-296. https://doi.org/10.1038/nmeth.4169

Rangan, R., Zheludev, I. N., Hagey, R. J., Pham, E. A., Wayment-Steele, H. K., Glenn, J. S., \& Das, R. (2020). RNA genome conservation and secondary structure in SARS-CoV-2 and SARS-related viruses: a first look. RNA (New York, N.Y.), 26(8), 937-959. https://doi.org/10.1261/rna.076141.120

Robertson, M. P., Igel, H., Baertsch, R., Haussler, D., Ares, M., Jr, \& Scott, W. G. (2005). The structure of a rigorously conserved RNA element within the SARS virus genome. PLoS Biology, 3(1), e5. https://doi.org/10.1371/journal.pbio.0030005

Singh, S.K., Koshkin, A.A., Wengel, J. and Nielsen, P. (1998) LNA (locked nucleic acids): synthesis and high-affinity nucleic acid recognition. Chem. Commun. 4, 455-456. doi: 10.1039/A708608C RNA SHAPE analysis in living cells. Nature Chemical Biology, 9(1), 18-20. https://doi.org/10.1038/nchembio.1131

Taiaroa, G., Rawlinson, D.,Featherstone, L, Pitt, M., Caly, L., Druce, J., Purcell, D., Harty, L.,Tran, T., Roberts, J., Catton, M., Williamson, D., Coin, L., Duchene, S. (2020). Direct RNA sequencing and early evolution of SARS-CoV-2. bioRxiv 2020.03.05.976167; doi: https://doi.org/10.1101/2020.03.05.976167

Tegunov, D., \& Cramer, P. (2019). Real-time cryo-electron microscopy data preprocessing with Warp. Nature Methods, 16(11), 1146-1152. https://doi.org/10.1038/s41592-019-0580-y

Tengs, T., \& Jonassen, C. M. (2016). Distribution and Evolutionary History of the Mobile Genetic Element s2m in Coronaviruses. Diseases (Basel, Switzerland), 4(3), 27. https://doi.org/10.3390/diseases4030027

Tengs, T., Kristoffersen, A. B., Bachvaroff, T. R., \& Jonassen, C. M. (2013). A mobile genetic element with unknown function found in distantly related viruses. Virology 
597 Vahed, M., Sweeney, A., Shirazi, F. H., Mirsaeidi, M. (2020). Mutation in position of 32

$598(\mathrm{G}>\mathrm{U})$ of S2M differentiate human SARS-CoV2 from Bat Coronavirus. bioRxiv

599

600 2020.09.02.280529; doi: https://doi.org/10.1101/2020.09.02.280529

601

van den Brink, E. N., Ter Meulen, J., Cox, F., Jongeneelen, M. A., Thijsse, A., Throsby, M.,

602 Marissen, W. E., Rood, P. M., Bakker, A. B., Gelderblom, H. R., Martina, B. E., Osterhaus, A. D., Preiser, W., Doerr, H. W., de Kruif, J., \& Goudsmit, J. (2005). Molecular and biological characterization of human monoclonal antibodies binding to the spike and nucleocapsid proteins of severe acute respiratory syndrome coronavirus. Journal of Virology, 79(3), 1635-1644. https://doi.org/10.1128/JVI.79.3.1635-1644.2005

607

Wacker, A., Weigand, J. E., Akabayov, S. R., Altincekic, N., Bains, J. K., Banijamali, E., Binas, O., Castillo-Martinez, J., Cetiner, E., Ceylan, B., Chiu, L. Y., Davila-Calderon, J., Dhamotharan, K., Duchardt-Ferner, E., Ferner, J., Frydman, L., Fürtig, B., Gallego, J., Grün, J. T., Hacker, C., ... Zetzsche, H. (2020). Secondary structure determination of conserved SARS-CoV-2 RNA elements by NMR spectroscopy. Nucleic Acids Research, gkaa1013. Advance online publication. https://doi.org/10.1093/nar/gkaa1013

Wahlestedt, C., Salmi, P., Good, L., Kela, J., Johnsson, T., Hökfelt, T., Broberger, C., 616 Porreca, F., Lai, J., Ren, K., Ossipov, M., Koshkin, A., Jakobsen, N., Skouv, J., Oerum, H., 617 Jacobsen, M. H., \& Wengel, J. (2000). Potent and nontoxic antisense oligonucleotides 618 containing locked nucleic acids. Proceedings of the National Academy of Sciences of the United States of America, 97(10), 5633-5638. https://doi.org/10.1073/pnas.97.10.5633

Yeh, T. Y., \& Contreras, G. P. (2020). Emerging viral mutants in Australia suggest RNA recombination event in the SARS-CoV-2 genome. The Medical journal of Australia, 213(1), 44-44.e1. https://doi.org/10.5694/mja2.50657 Uprichard, S. L., Wakita, T., \& Chisari, F. V. (2005). Robust hepatitis C virus infection in vitro. Proceedings of the National Academy of Sciences of the United States of America, 102(26), 9294-9299. https://doi.org/10.1073/pnas.0503596102 
bioRxiv preprint doi: https://doi.org/10.1101/2020 09.18.304139; this version posted March 11,2021 . The copyright holder for this preprint (which was not certified by peer review) is the author/funder, who has granted bioRxiv a license to display the preprint in perpetuity. It is made available under aCC-BY 4.0 International license.

\section{FIGURES}

634 
A

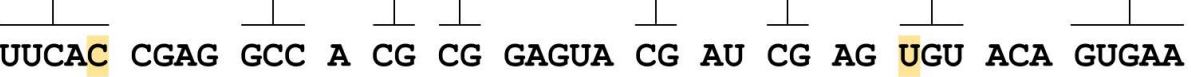

SARS-CoV-2

UUCAU CGAG GCC A C

B

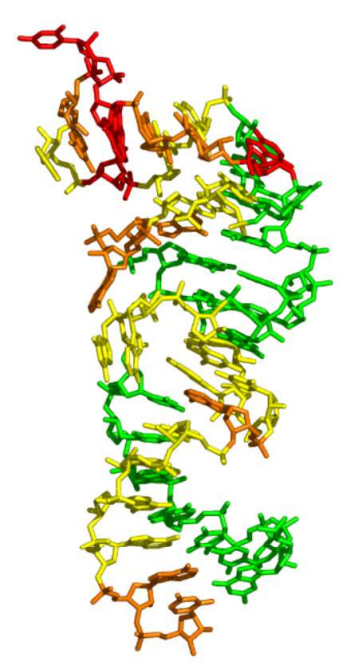

C
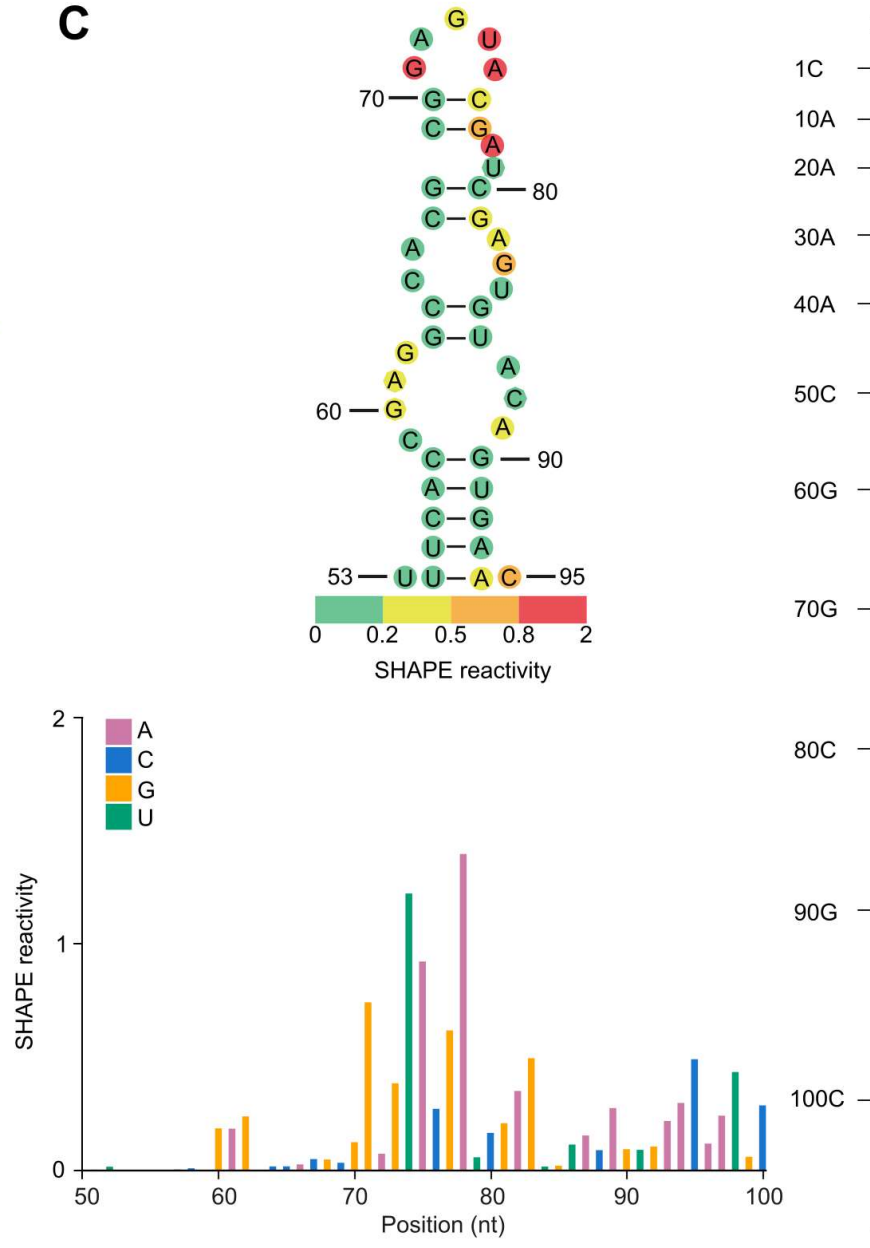

$\mathbf{E}$

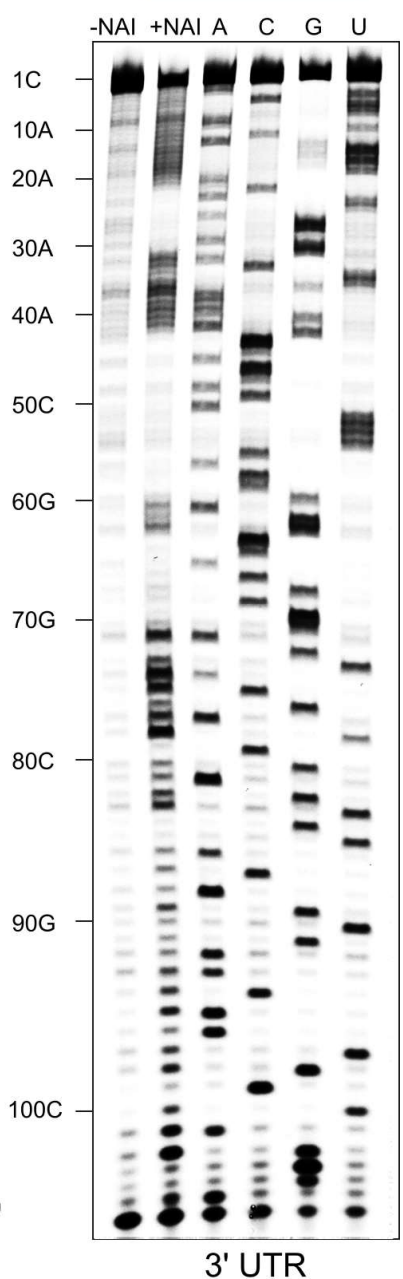

3' UTR
D

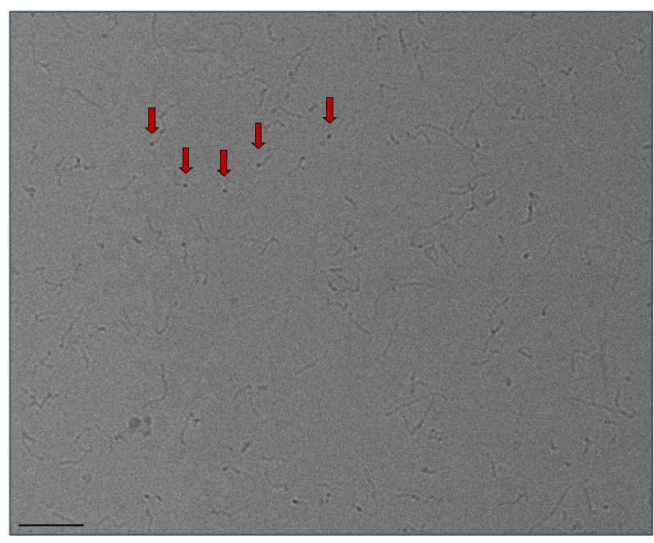

F

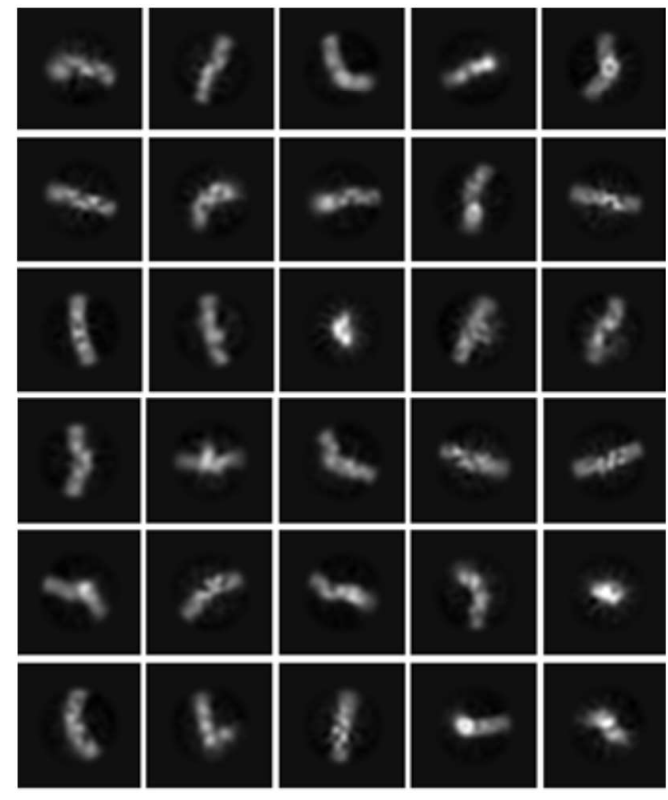


637 Figure 1. s2m is a conserved structural element in the SARS-CoV-2 genome. (A) Sequence

638 alignment of the s2m element in the 3' UTRs of SARS-CoV-2 and SARS-CoV. Lines indicate base-pairing regions within the element. (B) The crystal structure of the SARS-CoV s $2 \mathrm{~m}$ element (adapted from Robertson et al., 2005). (C) Chemical probing of the 3' UTR of SARSCoV-2. RNA was denatured and refolded in the presence of $100 \mathrm{mM} \mathrm{K}^{+}$and $0.5 \mathrm{mM} \mathrm{Mg}^{2+}$, then incubated with NAI (+NAI channel) or DMSO control (-NAI channel). NAI modification was detected by reverse transcription stalling and gel-based analysis. Sequencing lanes were generated by adding ddT (for A), ddG (for $\mathrm{C}$ ), ddC (for $\mathrm{G}$ ) and ddA (for $\mathrm{U}$ ) when performing reverse transcription. The lower panel shows quantification of SHAPE signal in the s2m and

646 flanking regions. Calculation was based on the gel in Fig. 1C, by subtracting the signal of the

647 +NAI lane from that of the -NAI lane. The upper panel shows annotation of SHAPE signal on

648 the s2m structure. The bases with SHAPE signal of 0-0.2, 0.2-0.5, 0.5-0.8 and 0.8-2 were coloured with green, yellow, orange and red, respectively. (D) Representative cryoEM image of the SARS-CoV-2 3' UTR (220 nt) at $2.5 \mu \mathrm{m}$ defocus. The red arrows indicate features that likely correspond to views along the long axis of duplex regions. The black line in the lower left is a $50 \mathrm{~nm}$ scalebar. (E) The 2D class averages and (F) 3D reconstructions as calculated by CryoSparc 2.15.0. 

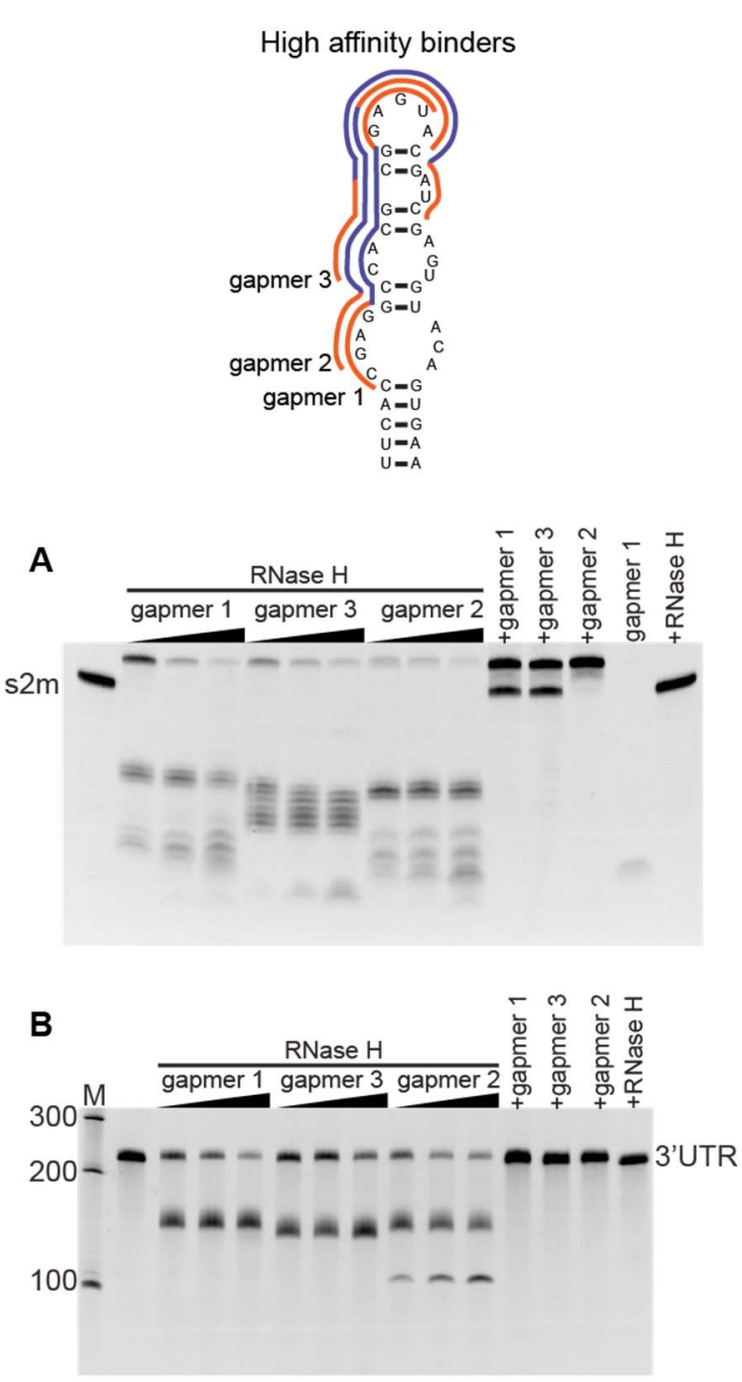

C

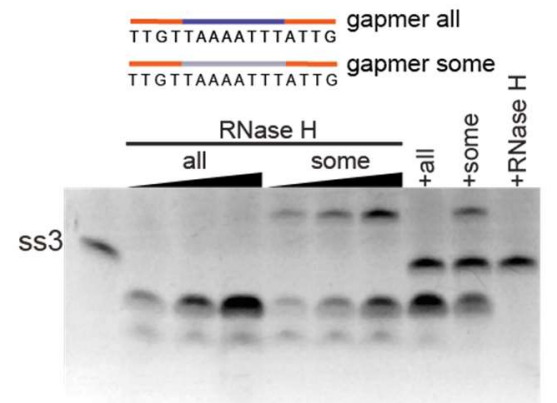

656

657

658

659

660

661

662

663

664

665

666

667
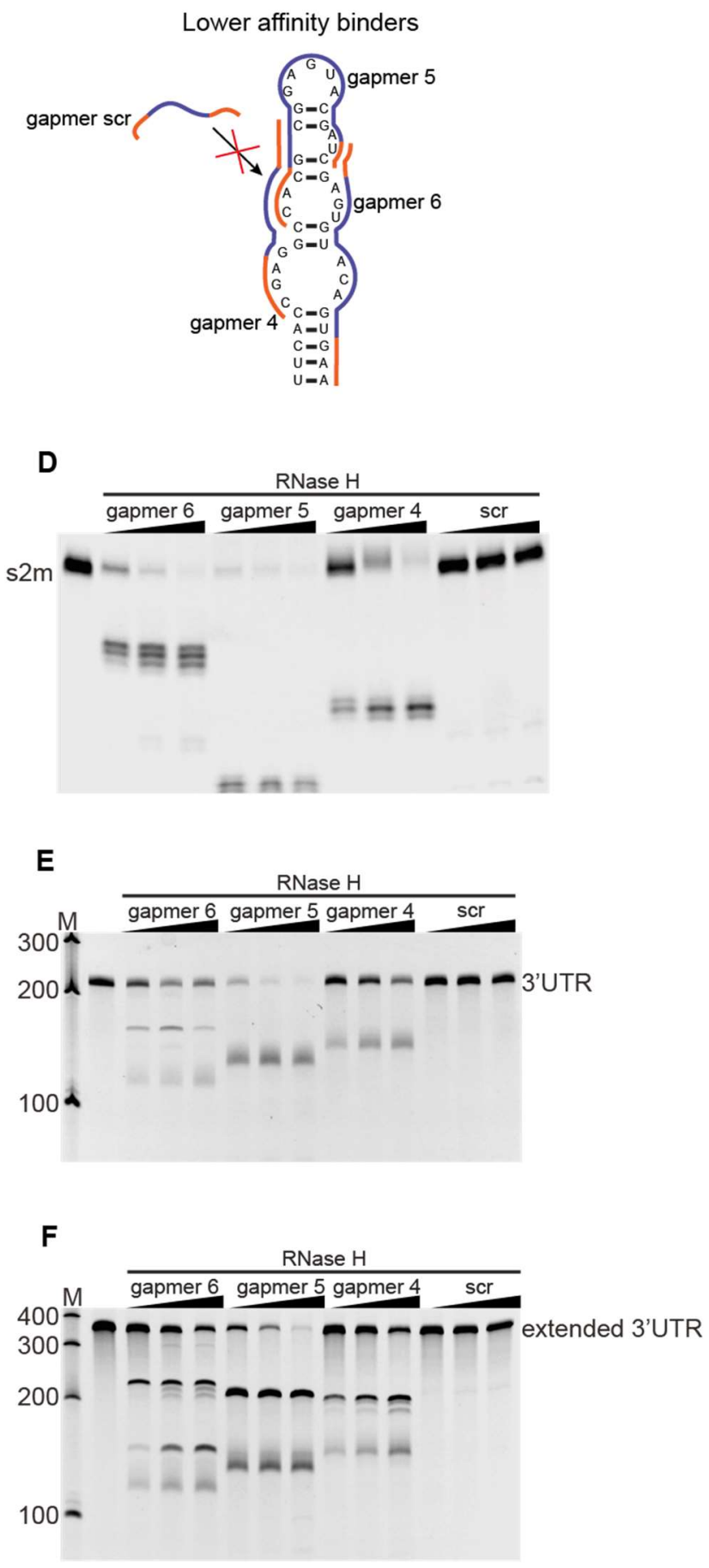

Figure 2. Antisense oligomers direct RNase $H$ cleavage of the $s 2 m$ element and a conserved single stranded region (ss3) in vitro. The upper panel shows the design of the six gapmers that are complementary to the $\mathrm{s} 2 \mathrm{~m}$ used in this study, as well as a non-specific control gapmer scr (Table 3). The LNA is indicated in orange, phosphorothioate-linked DNA in blue, phosphodiester-linked DNA in light grey. RNase $\mathrm{H}$ cleavage of the isolated s2m (A, D), $3^{\prime}$ UTR (B, E), the extended 3' UTR (F) and the predicted single-stranded region ss $3(\mathbf{C})$. Three target to gapmer molar ratios were tested: 1:05, 1:1 and 1:2. Incubation of RNA target with RNase $\mathrm{H}$ alone does not lead to cleavage (+RNase $\mathrm{H}$, last lane), and is not driven by control gapmers with scrambled DNA sequence (scr). Incubation of RNA target with gapmer without 

made available under aCC-BY 4.0 International license.

668 the addition of RNase $\mathrm{H}$ does not lead to degradation either, but does lead to the appearance of 669 a retarded band that likely corresponds to target:gapmer duplex. 
A
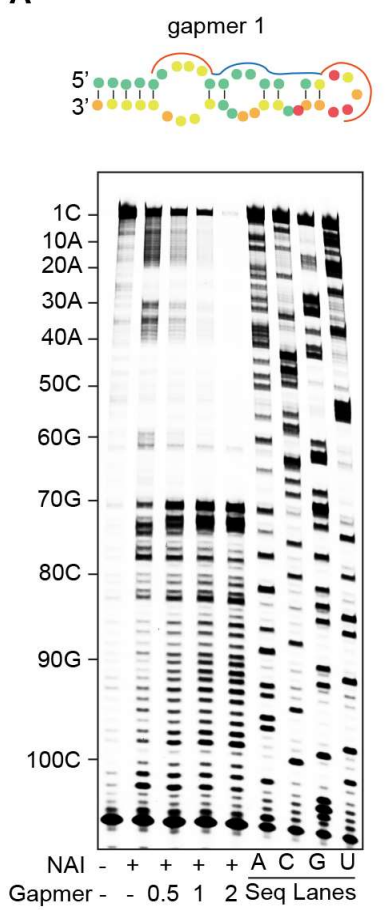

B
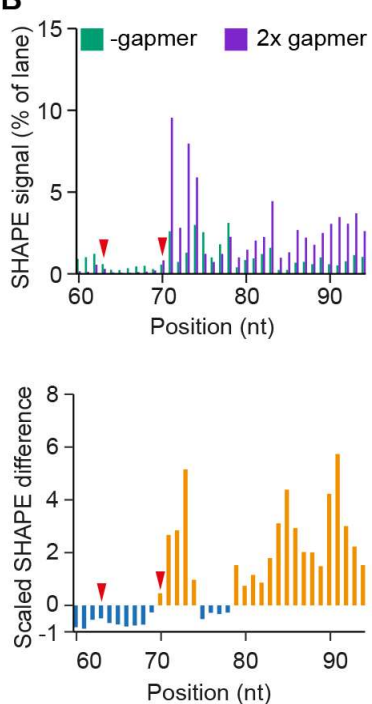

C
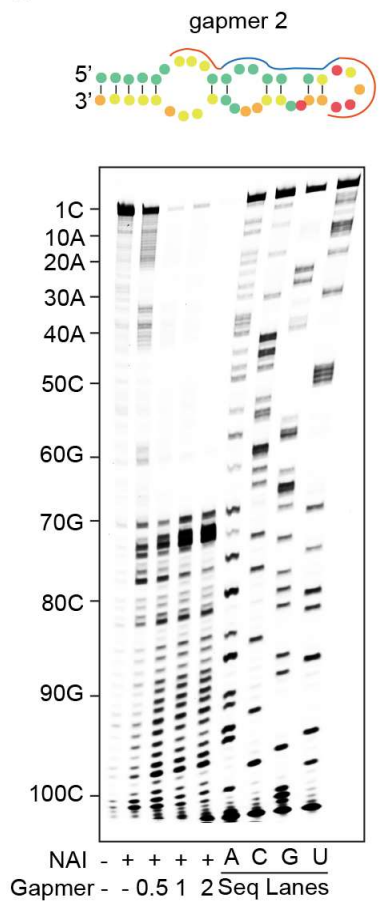

D
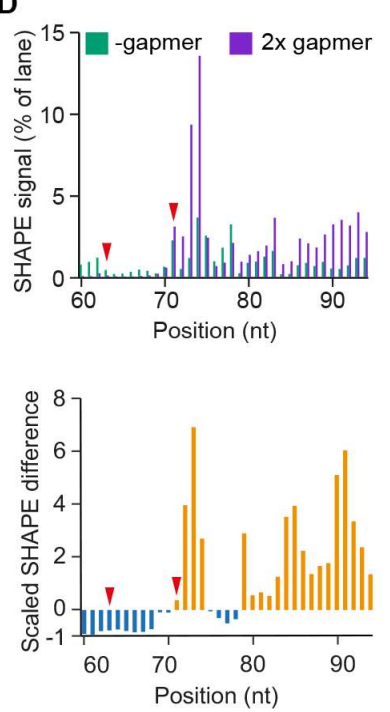

E
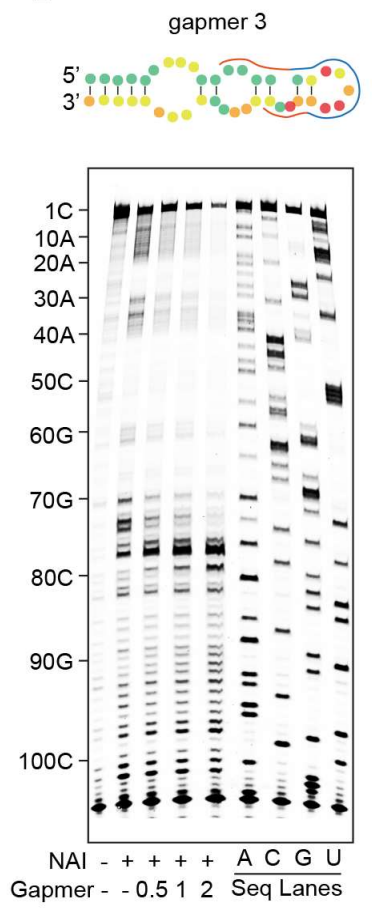

$\mathbf{F}$
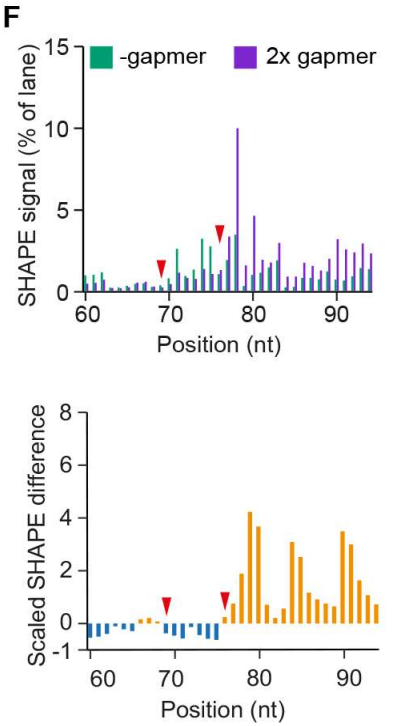

G
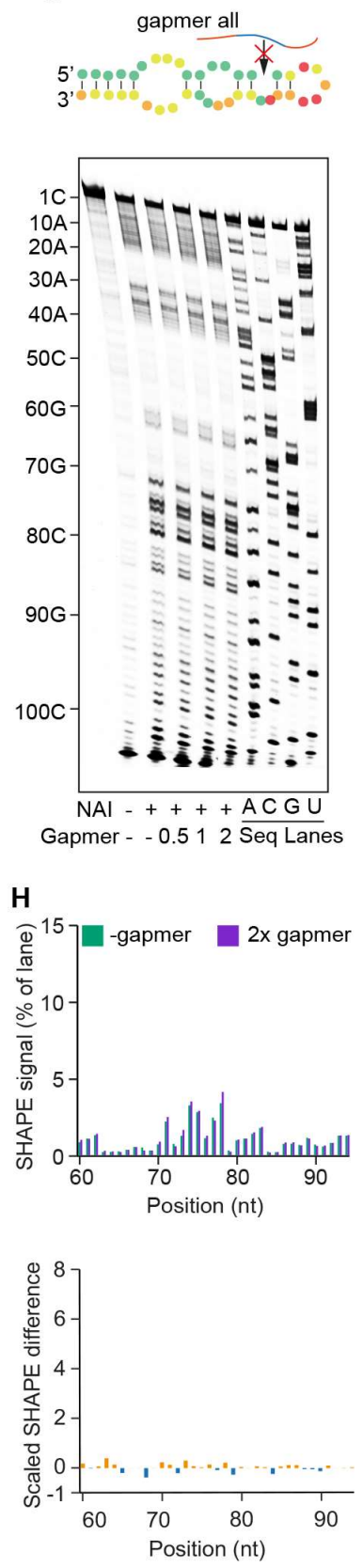

Figure 3. SHAPE probing reveals RNA structure changes induced by LNA gapmers. (A, gapmer indicated. RNA was denatured and refolded in the presence of $100 \mathrm{mM} \mathrm{K}^{+}$and $0.5 \mathrm{mM} \mathrm{Mg}^{2+}$, then incubated with different amounts of gapmer $(0 \times, 0.5 \times, 1 \times, 2 \times$ that of RNA) and probed using NAI. (B, D, F, H) Quantification of A, C, E and G, respectively. Analysis of the differences in SHAPE signal from SARS-CoV-2 3' UTR alone and in the presence of $2 \times$ gapmer. Red arrows indicate the start and end points of gapmer target regions. (A and $\mathbf{B}$ ) The presence of gapmer 1 induced an increase in SHAPE signal at positions 70-74 and 79-94, highlighted in orange, indicating that these nucleotides are more unstructured. A strong decrease in SHAPE signal was observed at positions 60-69, highlighted in blue, indicating decreased accessibility of these bases, which could be caused by their base-pairing with the gapmer. ( $\mathbf{C}$ and $\mathbf{D})$ The reactivity profile in $\mathbf{D}$ is similar to that in $\mathbf{B}$, due to the similar target regions of gapmer 1 and gapmer 2. (E and $\mathbf{F}$ ) In the presence of gapmer 3, nucleotides at positions 69-75 are more structured, while nucleotides at positions 76-94 are less structured, as 
indicated. ( $\mathbf{G}$ and $\mathbf{H})$ No significant differences in SHAPE signal could be detected in the presence or absence of the non-specific control gapmer "all", indicating that it is unable to cause structural changes in the SARS-CoV-2 3' UTR.

\section{A HeLa}

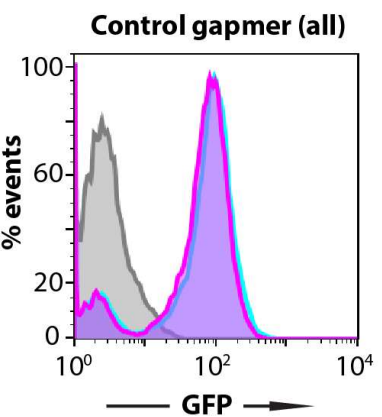

Control gapmer (scr)

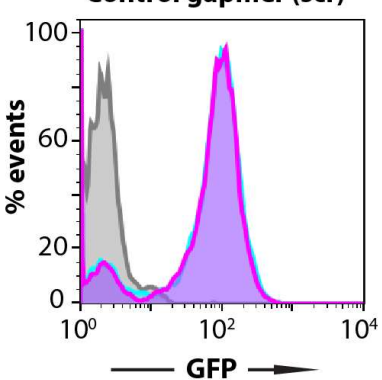

B
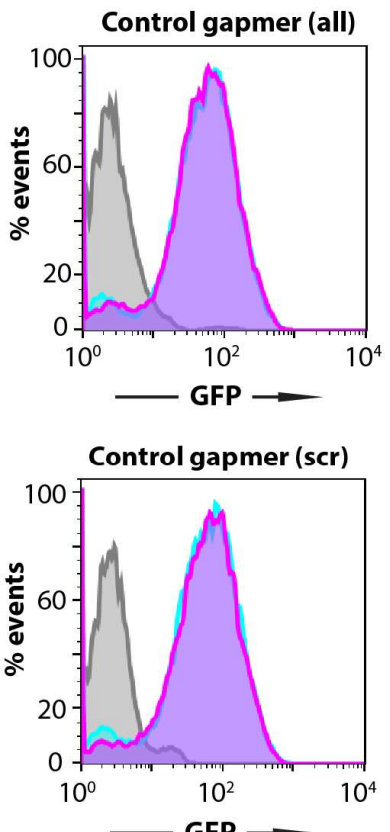

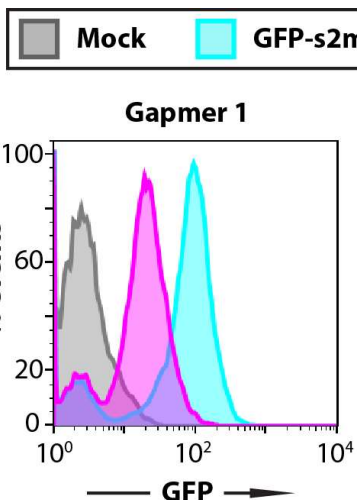

Gapmer 4
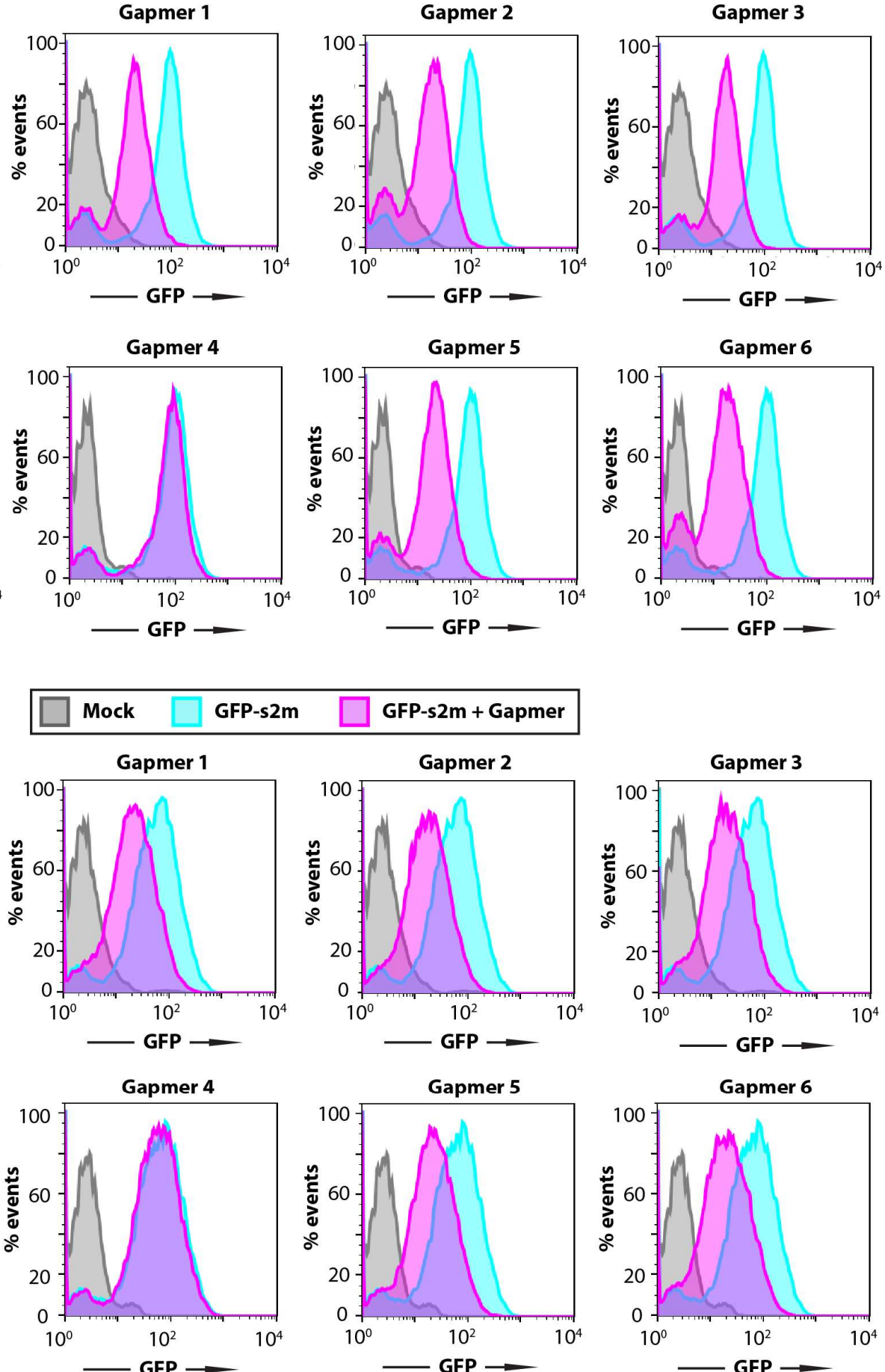
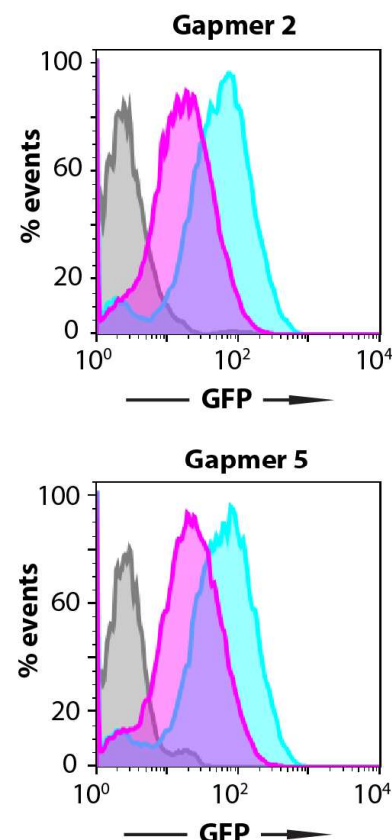
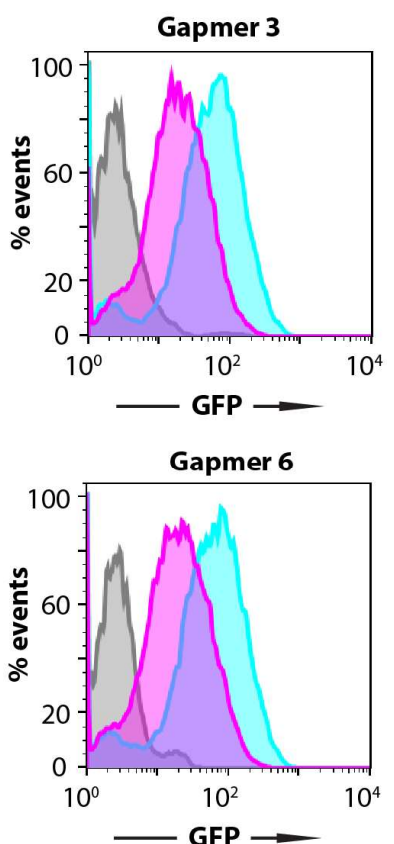

Figure 4. Gapmer-induced reduction of protein levels in cell reporter assays. Flow cytometry analysis of the GFP expressing cells. HeLa (A) and A549 (B) cell lines containing a genomic insertion of a GFP reporter construct with the s2m sequence in its 3' UTR (GFP$\mathrm{s} 2 \mathrm{~m}$ ) were transfected with $20 \mathrm{nM}$ of the indicated gapmers and analysed $72 \mathrm{~h}$ post-transfection 
696 by flow cytometry. Treatment with gapmers against the s2m element, but not a nonspecific 697 control gapmer, induced reduction in fluorescence, as detected by flow cytometry. Data are 698 representative of three independent experiments.

699 
A

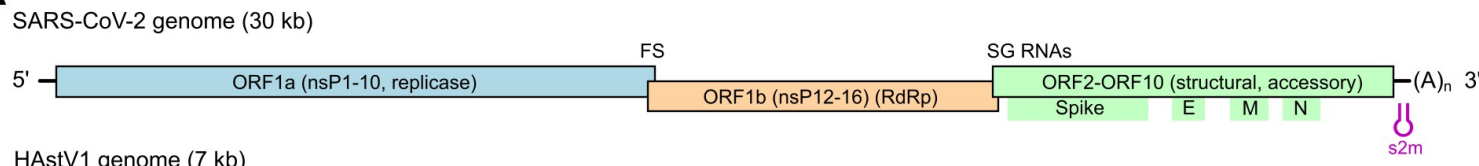

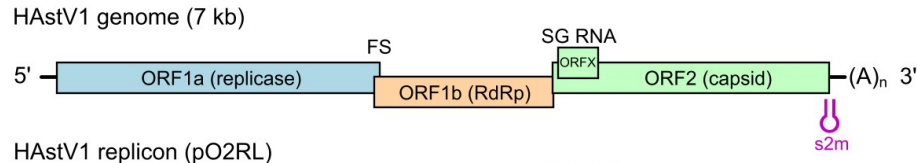

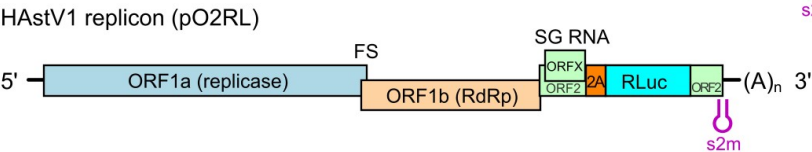

B
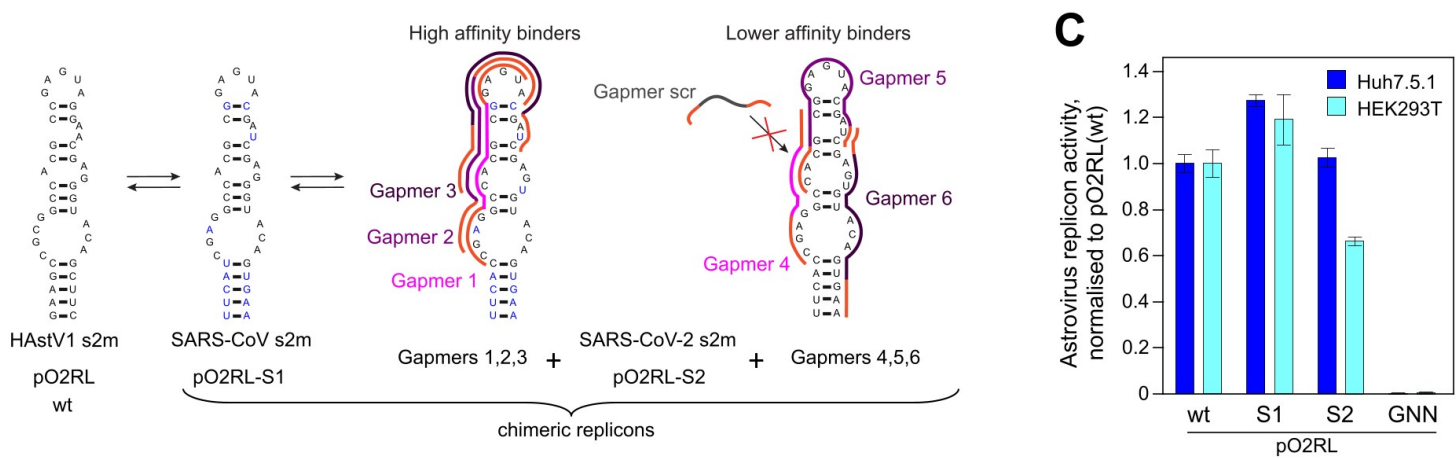

D

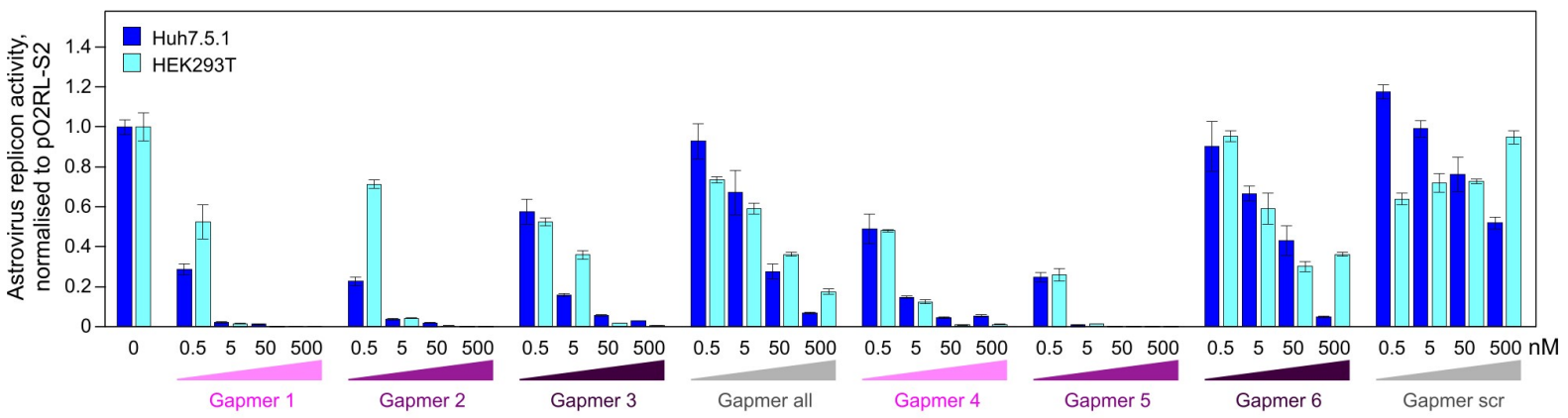

E

E 1.4 Huh7.5.1

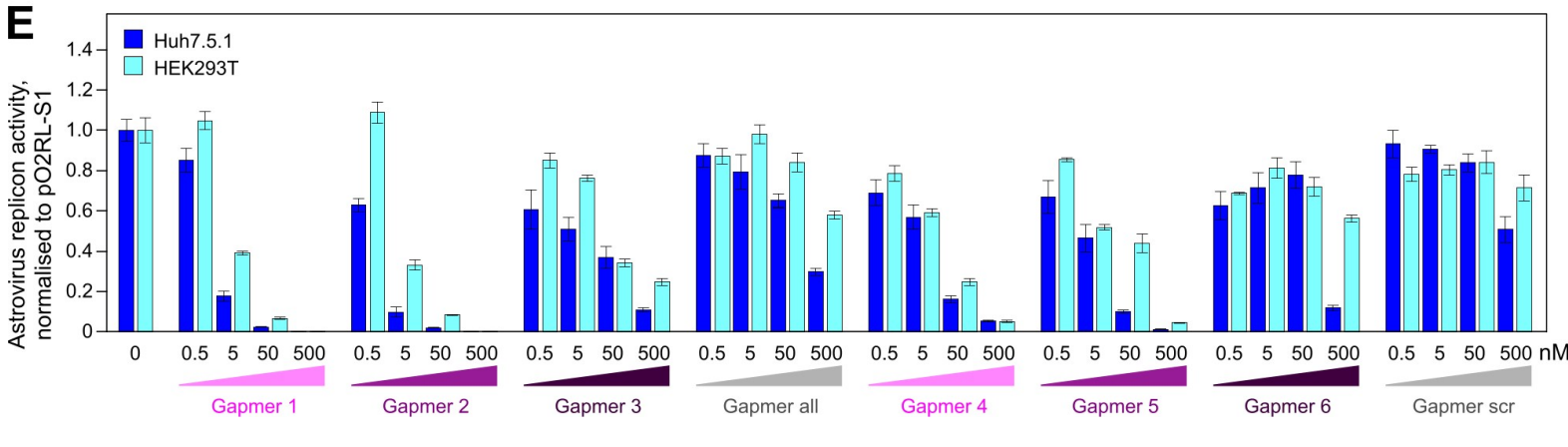

Figure 5. Inhibition of astrovirus replicon activity by gapmers targeting the SARS-CoV2 s2m RNA element. (A) Schematic of the SARS-CoV-2 and human astrovirus 1 (HAstV1) genome organisation. The lower panel represents the astrovirus replicon (pO2RL). FS, frameshift signal; SG, subgenomic; RLuc, Renilla luciferase; RdRp, RNA dependent RNA polymerase. The presented virus and replicon genomes are not to scale. (B) Conservation of the s2m 3' UTR element (two-dimensional representation) between HAstV1, SARS-CoV and SARS-CoV-2. In the astrovirus replicon, the HAstV1 s2m was switched for the SARS-CoV or SARS-CoV-2 s2m; the wild-type and chimeric replicons are indicated below. Gapmers $(1,2,3$ and $4,5,6)$ are colour-coded in light, medium and dark magenta, respectively. (C) Luciferase activity of the wildtype, chimeric, and replication-deficient (RdRp GDD motif mutated to GNN) astrovirus replicons measured in Huh7.5.1 (dark blue bars) and HEK293T (light blue 
713 bars) cells. (D) Inhibition of the SARS-CoV-2 chimeric replicon by gapmers at $0.5-500 \mathrm{nM}$ 714 concentration range. (E) Inhibition of the SARS-CoV chimeric replicon by gapmers at 0.5$715500 \mathrm{nM}$ concentration range. For D-E, all data are presented as mean \pm s.d.; $n=3$ biologically 716 independent experiments, full data and statistical analyses are provided in Supplementary 717 Tables S1 and S2. Replicon activity is presented as the ratio of Renilla (subgenomic reporter) 718 to Firefly (cap-dependent translation, loading control), normalized by the same ratio for the 719 untreated control replicon. 
A

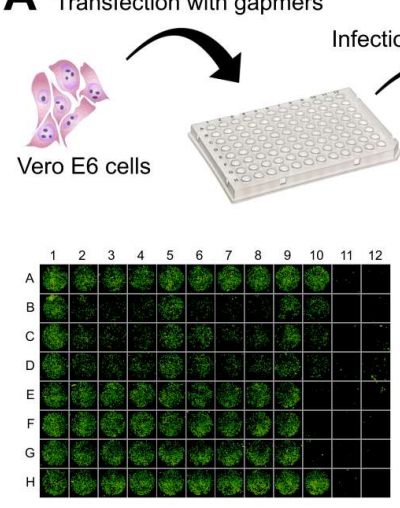

fection with SARS-CoV-2
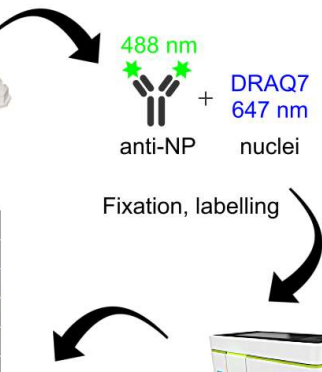

Screening, Image analysis
C

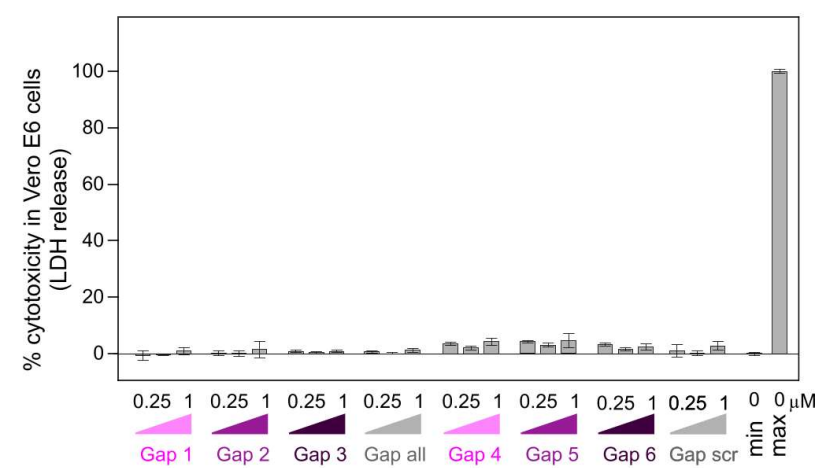

B

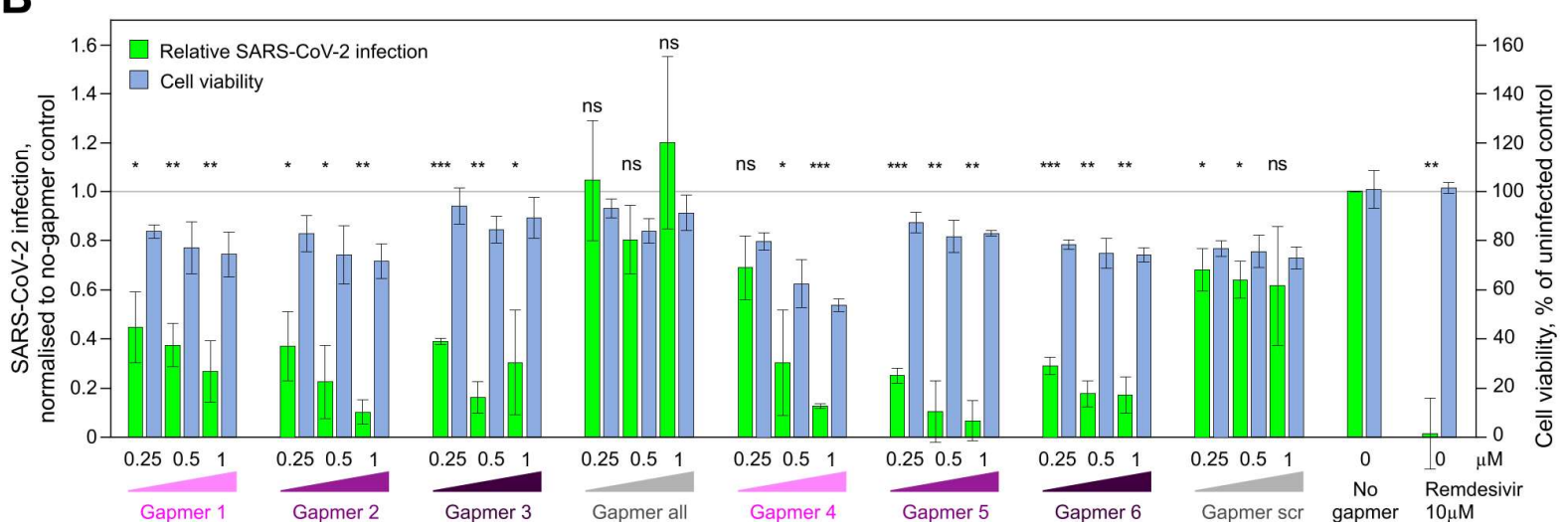

Figure 6. Inhibition of SARS-CoV-2 infection by gapmers targeting the s2m RNA element. (A) Graphic representation for the high content screening assay experiment workflow: transfection of Vero E6 cells with gapmers followed by infection with SARS-CoV2 , fixation of the plate, labelling and screening. A representative image from the immunofluorescence-based detection of SARS-CoV-2 infection of Vero E6 cells is shown below. (B) Vero E6 cells were transfected with gapmers 1-6 against the s2 m element or control gapmers "all" and "scr" at $0.25,0.5$, and $1 \mu \mathrm{M}$ final concentration and infected with SARS$\mathrm{CoV}-2$, fixed, labelled and analysed. Results are presented as mean \pm s.d.; $n=3$ biological replicates; signal normalised to a no-gapmer control. Cell viability was evaluated using the DRAQ7 signal normalised to mock treated wells. $P$-values are from two-tailed $t$-tests with separate variances (ns, $p>0.05 ; *, p \leq 0.05 ; * *, p \leq 0.01 ; * * *, p \leq 0.001$ ). (C) Toxicity assay for gapmer-treated Vero E6 cells in the absence of transfection reagent. Cells were treated with $0.25,0.5$, and $1 \mu \mathrm{M}$ gapmers for $24 \mathrm{~h}$. Supernatant was used to measure cell viability, calculated as the ratio of released to total lactate dehydrogenase (LDH) activity; "max" = maximum LDH measured for fully lysed cells. Full data and statistical analyses for B-C are provided in Supplementary Tables S3 and S4. 


\section{MATERIALS AND METHODS}

741

742

743

744

745

746

747

748

749

750

751

752

753

754

755

756

757

758

759

760

761

762

763

764

765

766

767

768

769

770

771

772

773

774

775

776

777

778

779

780

781

782

783

784

785

786

787

788

\section{RNA preparation}

3' UTRs and the s2m 47-mer were prepared by in vitro transcription (IVT). Templates for IVT were generated either by PCR, using Phire Hotstart II polymerase (Thermo Fisher) according to manufacturer's instructions, or by hybridising complementary DNA oligonucleotides (Sigma). Sequences for the PCR primers and the DNA oligonucleotides are given in Table 2. RNA generated by IVT was purified: IVT products were separated on polyacrylamide denaturing gel (National Diagnostics), relevant bands were excised using UV shadowing and electroeluted in TBE (Whatman Elutrap), then cleaned up using PureLinkTM RNA Microscale Kit (Invitrogen). RNA concentrations were estimated using UV absorbance (A260nm) and a calculated extinction coefficient.

\section{Gel-based RNA cleavage assay}

Each gapmer was pre-incubated with target RNA in $1 \times$ RNase H buffer (Thermo Scientific) for $10 \mathrm{~min}$ at $37^{\circ} \mathrm{C}$. $2.5 \mathrm{U}$ of RNase $\mathrm{H}$ (Thermo Scientific) was then added and the reaction incubated for $20 \mathrm{~min}$ at $37^{\circ} \mathrm{C}$. Reactions were quenched by adding an equal volume of proteinase $\mathrm{K}$ mix $(0.5 \mathrm{mg} / \mathrm{mL}$ enzyme, $100 \mathrm{mM}$ Tris- $\mathrm{HCl} \mathrm{pH} 7.5,150 \mathrm{mM} \mathrm{NaCl}$, $12.5 \mathrm{mM}$ EDTA, $1 \% \mathrm{w} / \mathrm{v}$ SDS) and incubating at $50{ }^{\circ} \mathrm{C}$ for $20 \mathrm{~min}$. RNA was visualised on polyacrylamide 7.5 M urea gel (National Diagnostics) in TBE using SybrGold (Invitrogen).

\section{Chemical probing of the 3' UTR}

To probe RNA structure without gapmers, 5 pmol RNA $(\sim 350 \mathrm{ng})$ was dissolved in $9 \mu 1$ nuclease-free water, and denatured at $95{ }^{\circ} \mathrm{C}$ for $90 \mathrm{~s}$, then cooled on ice for $2 \mathrm{~min}$. RNA was refolded by adding $10 \mu \mathrm{l}$ of $2 \times$ SHAPE probing buffer ( $80 \mathrm{mM}$ HEPES, $\mathrm{pH} 7.5,200 \mathrm{mM} \mathrm{KCl}$, $1 \mathrm{mM} \mathrm{MgCl}_{2}$ ) and incubating at $37^{\circ} \mathrm{C}$ for $15 \mathrm{~min}$. 2-methylnicotinic acid imidazolide (NAI) was added to a final concentration of $100 \mathrm{mM}$ in $20 \mu 1$ reaction; in control reactions, same volume of DMSO was added instead. Reactions were allowed to proceed at $37^{\circ} \mathrm{C}$ for 5 min and then quenched by adding $10 \mu \mathrm{l}$ of $2 \mathrm{M}$ DTT. RNA was purified by loading quenched samples onto Micro Bio-spin Columns with Bio-Gel P-6 (BioRad), followed by ethanol precipitation. Purified RNA was then dissolved in $6 \mu$ water, reverse-transcribed into cDNA and analysed by PAGE as described below.

To probe RNA structure with gapmers, different amounts of gapmers were added to refolded RNA, at molar ratios of $0.5 \times, 1 \times$ or $2 \times$, and incubated at $37^{\circ} \mathrm{C}$ for $10 \mathrm{~min}$. The same volume of water was added for the no-gapmer control. After co-incubation, RNA was probed using NAI as described above. In addition, un-probed input RNA was also subjected to Sanger sequencing: RNA was dissolved in $5 \mu \mathrm{l}$ water and supplemented with $1 \mu \mathrm{l}$ of $10 \mathrm{mM}$ corresponding ddNTP (Roche), then reverse-transcribed into cDNA and analysed by PAGE as described below.

\section{Reverse transcription and $P A G E$ analysis of $c D N A$}

$6 \mu \mathrm{l}$ of each RNA-containing sample was mixed with $1 \mu \mathrm{l}$ of $5 \mu \mathrm{M}$ Cy5-modified RT primer (sequence given in Table 2) and $0.5 \mu \mathrm{l}$ of $10 \mathrm{mM}$ dNTPs. The mixture was incubated at $95^{\circ} \mathrm{C}$ for $3 \mathrm{~min}$ to denature the RNA and then cooled to $50^{\circ} \mathrm{C}$. RT reaction was started by adding $2 \mu \mathrm{l}$ of $5 \times \mathrm{RT}$ buffer ( $100 \mathrm{mM}$ Tris $\mathrm{pH} 8.3,500 \mathrm{mM} \mathrm{LiCl}, 15 \mathrm{mM} \mathrm{MgCl}_{2}, 5 \mathrm{mM}$ DTT) and $0.5 \mu$ Superscript III enzyme (Invitrogen), mixing quickly with a pipette tip. Reaction was allowed to proceed at $50^{\circ} \mathrm{C}$ for $20 \mathrm{~min}$, then quenched by incubation at $85^{\circ} \mathrm{C}$ for $10 \mathrm{~min}$, which inactivates the enzyme. In order to degrade RNA and liberate the complementary cDNA, 
the reaction mix was then supplemented with $0.5 \mu \mathrm{l}$ of $2 \mathrm{M} \mathrm{NaOH}$ and incubated at $95^{\circ} \mathrm{C}$ for $10 \mathrm{~min}$. The reaction was stopped by adding an equal volume of $2 \times$ stopping buffer (95\% formaldehyde, $20 \mathrm{mM}$ EDTA $\mathrm{pH} 8.0,20 \mathrm{mM}$ Tris- $\mathrm{HCl} \mathrm{pH} \mathrm{7.5,} \mathrm{orange} \mathrm{G}$ dye) and incubating at $95^{\circ} \mathrm{C}$ for $5 \mathrm{~min}$. The resulting cDNA sample was cooled down to $65^{\circ} \mathrm{C}$ and analysed on an $8 \%$ Acrylamide:Bis-Acrylamide-Urea gel by electrophoresis. The gel was imaged using Typhoon FLA 9000 Gel Imager (GE healthcare).

\section{Quantitative Gel Analysis and SHAPE Reactivity Calculation}

Signal intensity of each band on the PAGE gel was detected using ImageQuant TL software and normalized to the total signal of the whole lane. Raw reactivity was generated by subtracting the signal of NAI channel from that of the DMSO control channel; reactivities with negative values were corrected to 0 . SHAPE reactivity was generated following the $2 / 8 \%$ normalization method (Low and Weeks, 2010). To calculate the differences in SHAPE signal in the presence and absence of gapmers, the lanes of NAI channels with $2 \times$ gapmer (+gapmer) or without gapmer (-gapmer) were used. The signal intensity of each band was normalized to the total signal of the whole lane. Differences were calculated by subtracting the signal of the +gapmer channel from that of the -gapmer channel and then rescaled to the signal of the gapmer channel.

\section{Cryo electron microscopy}

$5 \mu \mathrm{M}$ purified $3^{\prime} \mathrm{UTR}$ in $10 \mathrm{mM}$ Tris $\mathrm{pH} 7.6,10 \mathrm{mM} \mathrm{KCl}, 10 \mathrm{mM} \mathrm{NaCl}$ was annealed by sequential incubation at $95{ }^{\circ} \mathrm{C}$ for $2 \mathrm{~min}$, at $50{ }^{\circ} \mathrm{C}$ for $2 \mathrm{~min}$, at $37^{\circ} \mathrm{C}$ for $5 \mathrm{~min}$ and then at room temperature. The sample was supplemented with $1 \mathrm{mM} \mathrm{MgCl}_{2} .3 \mu 1$ of the resultant mixture was applied to glow-discharged (EasiGlow Pelco) R2/2 Quantifoil grids (Quantifoil). Excess sample was blotted away with a FEI Vitrobot (IV) $\left(100 \%\right.$ humidity, $4{ }^{\circ} \mathrm{C}$, blotting force $0,3 \mathrm{~s}$ blot time) and the grids were vitrified in liquid ethane. The grids were screened with a $200 \mathrm{kV}$ FEI Talos Arctica microscope with a Falcon III camera and a data set was collected on a $300 \mathrm{kV}$ FEI Titan Krios microscope equipped with a Gatan K3 camera. Motion correction, ctf estimation and particle-picking were performed in Warp (Tegunov and Cramer , 2019) and 2D/3D alignments and averaging were carried out with cryoSPARC 2.15 (Punjani et al., 2017).

\section{Gapmer reporter assays}

The $\mathrm{s} 2 \mathrm{~m}$ sequence or control scrambled sequence of $\mathrm{s} 2 \mathrm{~m}$ ( $\mathrm{s} 2 \mathrm{~m}$ scr) was inserted into the 3' UTR of GFP in H6P plasmid using In-Fusion Cloning kit (TaKaRa) and verified by sequencing. HEK293ET, HeLa and A459 cells, as well as all stable cell lines, were grown in IMDM medium supplemented with $10 \% \mathrm{FCS}$ at $37{ }^{\circ} \mathrm{C}$ in $5 \% \mathrm{CO}_{2}$. All cell lines tested negative for mycoplasma. Constructs in H6P plasmids were used to produce recombinant lentivirus in HEK293ET cells for the stable expression of GFP reporter in mammalian cells from a constitutive SFFV promoter. HeLa and A549 stable cell lines were generated by lentiviral transduction with low MOI $(>0.3)$ to ensure single genomic integrations and were selected for by drug resistance.

To examine the effect of gapmers on GFP expression, HeLa or A549 cells with a stably integrated GFP-s $2 \mathrm{~m} / \mathrm{s} 2 \mathrm{~m} \_$scr reporter were seeded at $5 \times 10^{4}$ cells per well in 24 -well plates. The following day, cells were transfected with gapmer to achieve $20 \mathrm{nM}$ final concentration using Lipofectamine RNAiMAX (Thermo Fisher Scientific). Flow cytometry analysis was performed $72 \mathrm{~h}$ after transfection. Cells were washed twice with warm PBS, detached with trypsin and resuspended in IMDM. All samples were analysed on a BD LSR ii flow cytometer, using the high throughput system (HTS), and at least 20,000 events were acquired for each sample. Data were analysed in FlowJo (v10.7.1). Main cell population was identified and gated 
839 on Forward and Side Scatter using the Auto Gate tool and plotted as a histogram to visualise GFP intensity of cells (measured using B-525 detector).

\section{Virus replicon assays}

HEK293T cells (ATCC) were maintained at $37{ }^{\circ} \mathrm{C}$ in DMEM supplemented with $10 \%$ fetal bovine serum (FBS), 1 mM L-glutamine, and antibiotics. Huh7.5.1 cells (obtained from Apath, Brooklyn, NY; Zhong et al., 2005) were maintained in the same media supplemented with nonessential amino acids. All cells were mycoplasma tested (MycoAlert ${ }^{\mathrm{TM}}$ PLUS Assay, Lonza); Huh7.5.1 cells were also tested by deep sequencing.

The HAstV1 replicon system is based on the HAstV1 infectious clone, where the virus genome is left intact up to the end of ORFX, then followed by a foot-and-mouth disease virus $2 \mathrm{~A}$ sequence and a Renilla luciferase (RLuc) sequence fused in the ORF2 reading frame, followed by the last $624 \mathrm{nt}$ of the virus genome and a poly-A tail (Fig. 4A, GenBank accession number MN030571; Lulla and Firth, 2020). The s2m mutations were introduced using site-directed mutagenesis and all constructs were confirmed by sequencing. The resulting plasmids were linearized with $\mathrm{XhoI}$ prior to T7 RNA transcription.

Huh7.5.1 and HEK293T cells were transfected in triplicate with Lipofectamine 2000 reagent (Invitrogen), using the protocol in which suspended cells are added directly to the RNA complexes in 96-well plates. For each transfection, $100 \mathrm{ng}$ replicon, $10 \mathrm{ng}$ firefly luciferase-

860 encoding purified T7 RNA (RNA Clean and Concentrator, Zymo research), the indicated amount of gapmers, and $0.3 \mu \mathrm{l}$ Lipofectamine 2000 in $20 \mu \mathrm{l}$ Opti-Mem (Gibco) supplemented with RNaseOUT (Invitrogen; diluted 1:1,000 in Opti-Mem) were added to each well containing $5 \times 10^{4}$ cells in $100 \mu 1$ DMEM supplemented with $5 \%$ FBS, and incubated at $37^{\circ} \mathrm{C}$ for $12 \mathrm{~h}$ (Huh7.5.1) or 18 h (HEK293T). Firefly and Renilla luciferase activities were determined using the Dual Luciferase Stop \& Glo Reporter Assay System (Promega). Replicon activity was calculated as the ratio of Renilla (subgenomic reporter) to Firefly (cap-dependent translation, loading control), normalized by the same ratio for the control replicon, as indicated for each experiment. Three independent experiments, each in triplicate, were performed to confirm reproducibility of results.

\section{Cytotoxicity assays}

873

874

The analysis of gapmer cellular cytotoxicity in HEK293T, Huh7.5.1, and Vero E6 cells was performed using the CyQUANT LDH cytotoxicity assay (Thermo Scientific). Leaked cytoplasmic enzyme LDH in cell culture supernatants was quantified after enzymatic conversion, and absorbance was measured at $490 \mathrm{~nm}$ in a 96-well plate reader according to the manufacturer's instructions.

\section{SARS-CoV-2 production and infection}

880 DMEM modified with high glucose, L-glutamine, phenol red and sodium pyruvate 881 (ThermoFisher, \#41966-029) supplemented with 10\% FCS at 5\% $\mathrm{CO}_{2}$. SARS-CoV-2 strain BetaCoV/England/02/2020 (obtained from Public Health England) was propagated at $37^{\circ} \mathrm{C}$ on Vero E6 cells in DMEM supplemented with $10 \% \mathrm{FCS}$ at $37^{\circ} \mathrm{C}$. The titer was determined by plaque assay as follows: confluent monolayers of VeroE6 cells where grown on 6-well plates and incubated with $200 \mu \mathrm{l}$ of a 10 -fold serial dilution of virus stock in DMEM supplemented with $10 \%$ FCS for $1 \mathrm{~h}$ at room temperature. These cells were then overlaid with $0.5 \times$ DMEM supplemented with 1\% FCS and 1.2\% Avicel (BMC Biopolymers, Belgium). After 4 days incubation at $37{ }^{\circ} \mathrm{C}$, cells were fixed with $4 \%$ formaldehyde in PBS followed by staining with 
0.1\% toluidine blue (Sigma, \#89640). The titer was calculated as plaque forming units (PFU) per ml.

891

892

893

894

895

896

897

898

899

900

901

902

903

904

905

906

907

908

909

910

911

912

913

914

\section{SARS-CoV-2 infection assay}

Vero E6 cells (NIBC, UK) were grown in DMEM (containing $10 \% \mathrm{FBS}$ ) at $37^{\circ} \mathrm{C}$ and $5 \%$ $\mathrm{CO}_{2}$ in 96 well imaging plates (Greiner 655090). Cells were transfected with individual gapmers at $0.25,0.5$ or $1 \mu \mathrm{M}$ final concentration using Lipofectamine 2000 (Thermo Fisher), according to manufacturer's instructions. At $6 \mathrm{~h}$ post transfection, the media was replaced and the cells were infected or mock infected with SARS-CoV-2 at a multiplicity of infection $0.5 \mathrm{PFU} /$ cell. At $22 \mathrm{~h}$ post-infection, cells were fixed, permeabilised and stained for SARSCoV-2 N protein using Alexa488-labelled-CR3009 antibody (van den Brink et al., 2005) and for nuclei (DRAQ7, $647 \mathrm{~nm}$ wavelength). The plate was imaged using the high content screening microscope Opera Phenix from Perkin Elmer with a $5 \times$ lens. The Opera Phenixassociated software Harmony was used to delineate the whole well area and to determine the total intensities of the Alexa488/N protein and DRAQ7/DNA signals per said whole well area during image acquisition. The background subtracted Alexa488/N intensities were normalised to vehicle treated samples. Toxicity was evaluated using the DRAQ7/DNA signal normalised to mock treated wells and LDH release-based cytotoxicity assay.

\section{TABLES}

\section{Table 1. Sequence of the RNA used in this study}

The sequence in bold corresponds to the extended $\mathrm{s} 2 \mathrm{~m}$ region common for these RNA substrates.

SARS-CoV-2 s2m sequence used in RNase $\mathrm{H}$ assays in vitro and in GFP reporter assays (47 nt)

GGAGUUCACCGAGGCCACGCGGAGUACGAUCGAGUGUACAGUGAAUU

Scrambled control sequence used in GFP reporter assays (47 nt)

AGCCGGGCUGGAAGAUACUGCCCAAAUAGGGAACUUUGACGCGGUUG

SARS-CoV-2 3' UTR (220 nt)

UAGCAAUCUUUAAUCAGUGUGUAACAUUAGGGAGGACUUGAAAGAGCCACCACAUUUUCAC CGAGGCCACGCGGAGUACGAUCGAGUGUACAGUGAACAAUGCUAGGGAGAGCUGCCUAUA UGGAAGAGCCCUAAUGUGUAAAAUUAAUUUUAGUAGUGCUAUCCCCAUGUGAUUUUAAUAG CUUCUUAGGAGAAUGACAAAAAAAAAAAAAAAAAAAAA

SARS-CoV-2 extended 3' UTR (358 nt)

ACUCAUGCAGACCACACAAGGCAGAUGGGCUAUAUAAACGUUUUCGCUUUUCCGUUUACGAU AUAUAGUCUACUCUUGUGCAGAAUGAAUUCUCGUAACUACAUAGCACAAGUAGAUGUAGUU AACUUUAAUCUCACAUAGCAAUCUUUAAUCAGUGUGUAACAUUAGGGAGGACUUGAAAGAG CCACCACAUUUUCACCGAGGCCACGCGGAGUACGAUCGAGUGUACAGUGAACAAUGCUAG GGAGAGCUGCCUAUAUGGAAGAGCCCUAAUGUGUAAAAUUAAUUUUAGUAGUGCUAUCCCC AUGUGAUUUUAAUAGCUUCUUAGGAGAAUGACAAAAAAAAAAAAAAAAAAAAA

SARS-CoV-2 ss3 (16 nt). A conserved region predicted to be single-stranded in the genome; positions 13591374 relative to the NC_045512.2 reference (Rangan et al., 2020)

UUGUUAAAAUUUAUUG 
bioRxiv preprint doi: https://doi. org/10.1101/2020.09.18.304139. this version posted March 11 2021. The copyriaht holder for this preprint (which was not certified by peer review) is the author/funder, who has granted bioRxiv a license to display the preprint in perpetuity. It is made available under aCC-BY 4.0 International license. 


\section{Table 2. Primers for IVT and SHAPE analysis}

918

\begin{tabular}{|l|l|l|}
\hline Name & Type & Sequence \\
\hline $3^{\prime}$ UTR_F & IVT primer & $\begin{array}{l}\text { GTTTTTTAATACGACTCACTATAGCAATCTTTAATCAGTGTG } \\
\text { TAACATTAGG }\end{array}$ \\
\hline Extended 3' UTR_F & IVT primer & $\begin{array}{l}\text { GTTTTTTAATACGACTCACTATTACTCATGCAGACCACACA } \\
\text { AGGC }\end{array}$ \\
\hline 3' UTR_R & IVT primer & TTTTTTTTTTTTTTTTTTTTTGTCATTCTCCTAAGAAGC \\
\hline S2M_F & IVT primer & $\begin{array}{l}\text { GTTTTTTAATACGACTCACTATAGGAGTTCACCGAGGCCAC } \\
\text { GCGGAGTACGATCGAGTGTACAGTGAATT }\end{array}$ \\
\hline S2M_R & IVT primer & $\begin{array}{l}\text { AATTCACTGTACACTCGATCGTACTCCGCGTGGCCTCGGTG } \\
\text { AACTCCTATAGTGAGTCGTATTAAAAAAC }\end{array}$ \\
\hline COV19_RT1 & SHAPE Primer & Cy5-TTTTGTCATTCTCCTAAGAAGCT \\
\hline COV19_RT2 & SHAPE Primer & Cy5-CTCTTCCATATAGGCAGCTC \\
\hline
\end{tabular}




\section{Table 3 Gapmers used in this study}

922

923 Notation: $*=$ phosphorothioate backbone linkage; $[+\mathrm{X}]=$ LNA base $\mathrm{X}$.

924 Melting temperature predictions were obtained using an online oligo design tool

925 (https://www.qiagen.com/).

926

927

\begin{tabular}{|c|c|c|c|}
\hline Name & Sequence & $\begin{array}{l}\text { DNA } \\
\mathrm{T}_{\mathrm{m}}\left({ }^{\circ} \mathrm{C}\right)\end{array}$ & $\begin{array}{l}\text { RNA T } \\
\left({ }^{\circ} \mathrm{C}\right)\end{array}$ \\
\hline Gapmer 1 & {$[+\mathrm{A}]^{*}[+\mathrm{C}]^{*}[+\mathrm{T}] *[+\mathrm{C}]^{*} \mathrm{C} * \mathrm{G} * \mathrm{C} * \mathrm{G}^{*} \mathrm{~T} * \mathrm{G}^{*} \mathrm{G} * \mathrm{C} *[+\mathrm{C}]^{*}[+\mathrm{T}] *[+\mathrm{C}] *[+\mathrm{G}]$} & 85 & 93 \\
\hline Gapmer 2 & {$[+\mathrm{T}] *[+\mathrm{A}] *[+\mathrm{C}] *[+\mathrm{T}] * \mathrm{C} * \mathrm{C} * \mathrm{G} * \mathrm{C} * \mathrm{G} * \mathrm{~T} * \mathrm{G} * \mathrm{G} *[+\mathrm{C}] *[+\mathrm{C}] *[+\mathrm{T}] *[+\mathrm{C}]$} & 81 & 97 \\
\hline Gapmer 3 & {$[+\mathrm{G}] *[+\mathrm{A}] *[+\mathrm{T}] *[+\mathrm{C}] * \mathrm{G} * \mathrm{~T} * \mathrm{~A} * \mathrm{C} * \mathrm{~T} * \mathrm{C} * \mathrm{C} * \mathrm{G} *[+\mathrm{C}] *[+\mathrm{G}] *[+\mathrm{T}] *[+\mathrm{G}]$} & 78 & 88 \\
\hline Gapmer 4 & {$[+\mathrm{G}] *[+\mathrm{C}] * \mathrm{G} * \mathrm{~T} * \mathrm{G} * \mathrm{G} * \mathrm{C} * \mathrm{C} *[+\mathrm{T}] *[+\mathrm{C}] *[+\mathrm{G}]$} & 69 & 76 \\
\hline Gapmer 5 & {$[+\mathrm{G}] *[+\mathrm{A}] * \mathrm{~T} * \mathrm{C} * \mathrm{G} * \mathrm{~T} * \mathrm{~A} * \mathrm{C} * \mathrm{~T} * \mathrm{C} * \mathrm{C} * \mathrm{G} * \mathrm{C} *[+\mathrm{G}] *[+\mathrm{T}] *[+\mathrm{G}]$} & 70 & 76 \\
\hline Gapmer 6 & {$[+\mathrm{T}] *[+\mathrm{T}] *[+\mathrm{C}] * \mathrm{~A} * \mathrm{C} * \mathrm{~T} * \mathrm{G} * \mathrm{~T} * \mathrm{~A} * \mathrm{C} * \mathrm{~A} * \mathrm{C} * \mathrm{~T} *[+\mathrm{C}] *[+\mathrm{G}] *[+\mathrm{A}]$} & 68 & 79 \\
\hline scr & {$[+\mathrm{A}] *[+\mathrm{C}] * \mathrm{C} * \mathrm{G} * \mathrm{~T} * \mathrm{G} * \mathrm{C} * \mathrm{G} * \mathrm{G} * \mathrm{~T} * \mathrm{~A} * \mathrm{~T} * \mathrm{~T} *[+\mathrm{C}] *[+\mathrm{G}] *[+\mathrm{C}]$} & 71 & 75 \\
\hline all & {$[+\mathrm{C}]^{*}[+\mathrm{A}]^{*}[+\mathrm{A}]^{*}[+\mathrm{T}]^{*} \mathrm{~A} * \mathrm{~A} * \mathrm{~A} * \mathrm{~T} * \mathrm{~T} * \mathrm{~T} * \mathrm{~T} * \mathrm{~A} *[+\mathrm{A}]^{*}[+\mathrm{C}] *[+\mathrm{A}] *[+\mathrm{A}]$} & 53 & 50 \\
\hline some & {$[+\mathrm{C}] *[+\mathrm{A}] *[+\mathrm{A}] *[+\mathrm{T}] \mathrm{AAATTTTA}[+\mathrm{A}] *[+\mathrm{C}] *[+\mathrm{A}] *[+\mathrm{A}]$} & 53 & 50 \\
\hline
\end{tabular}


A

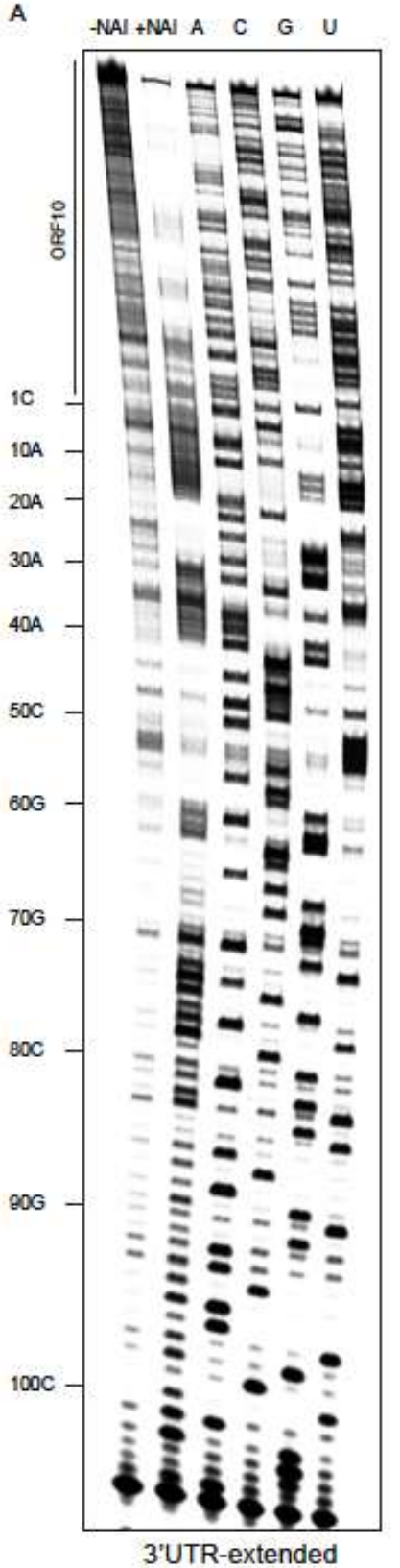

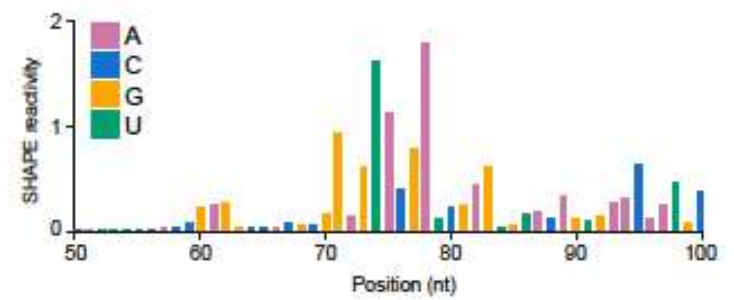

C

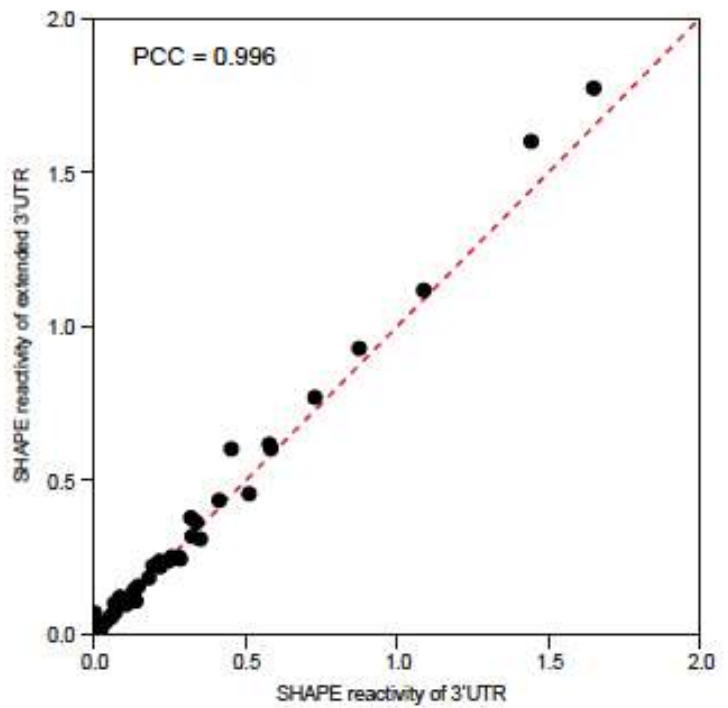

Figure S1, related to Figure 1. SHAPE analysis of the extended 3' UTR of SARS-CoV-2 (A) Chemical probing of the extended 3' UTR of SARS-CoV-2 (including ORF10 and the region immediately upstream of it). RNA was denatured and refolded in the presence of $100 \mathrm{mM} \mathrm{K}^{+}$and $0.5 \mathrm{mM} \mathrm{Mg}^{2+}$, then incubated with NAI (+NAI channel) or DMSO control (NAI channel). NAI modification was detected by reverse transcription stalling and gel-based analysis. Sequencing lanes were generated by adding ddT (for A), ddG (for C), ddC (for G) and ddA (for $\mathrm{U}$ ) when performing reverse transcription. (B) Quantification of SHAPE signal on at the s2m element and flanking regions. Calculation was based on the gel in Fig. S1A, by subtracting the signal of the +NAI lane from that of the -NAI lane. (C) Agreement of SHAPE signal on s2m structure in the 3' UTR and the extended 3' UTR of SARS-CoV-2. Pearson correlation coefficient was calculated based on the SHAPE signals shown in Fig. 1C and Fig. S1B. 
A

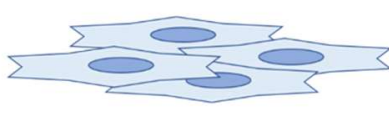

human cells
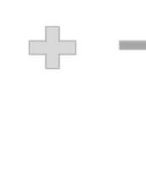

\section{GFP ORF}

reporter construct (genomically integrated)

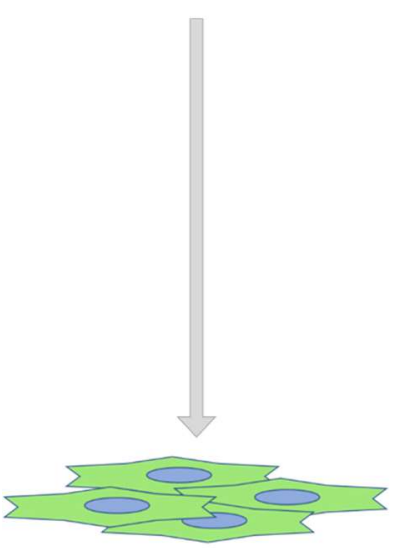

GFP expression

946

B

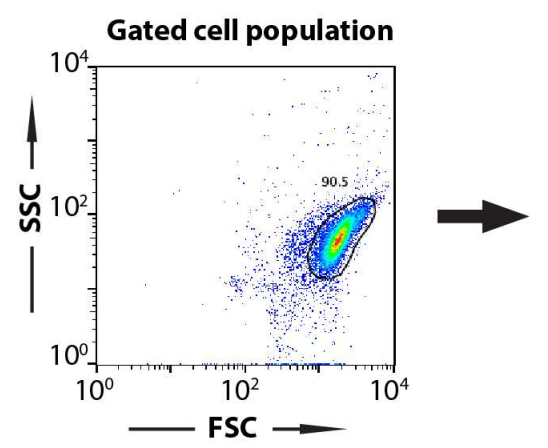

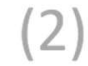

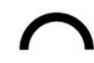
LNA gapmer non-specific

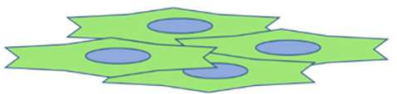

GFP expression

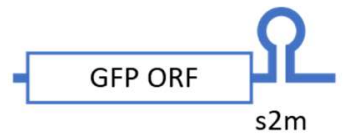

mRNA product

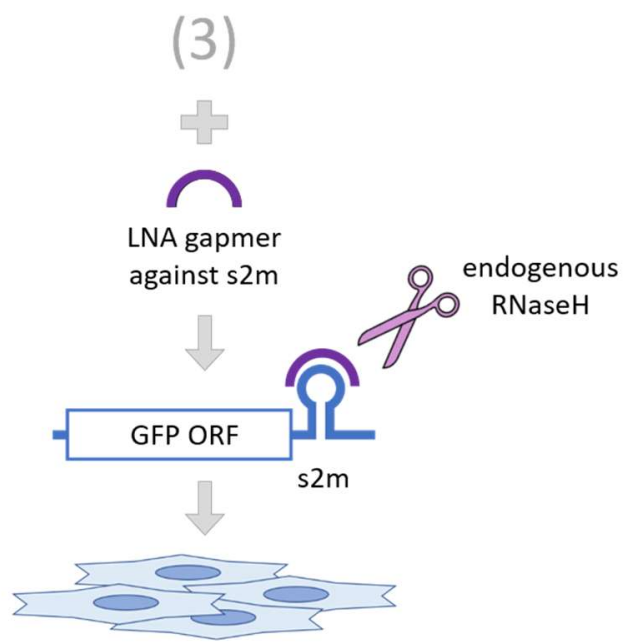

no GFP expression
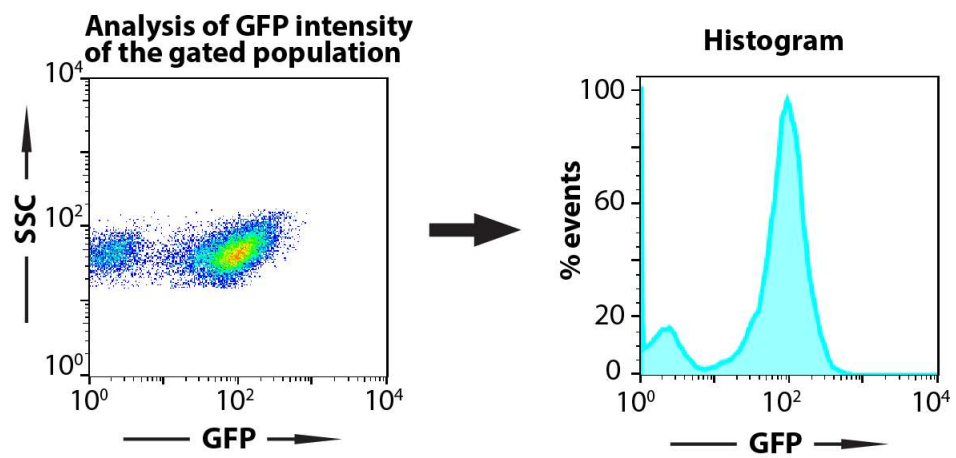

C
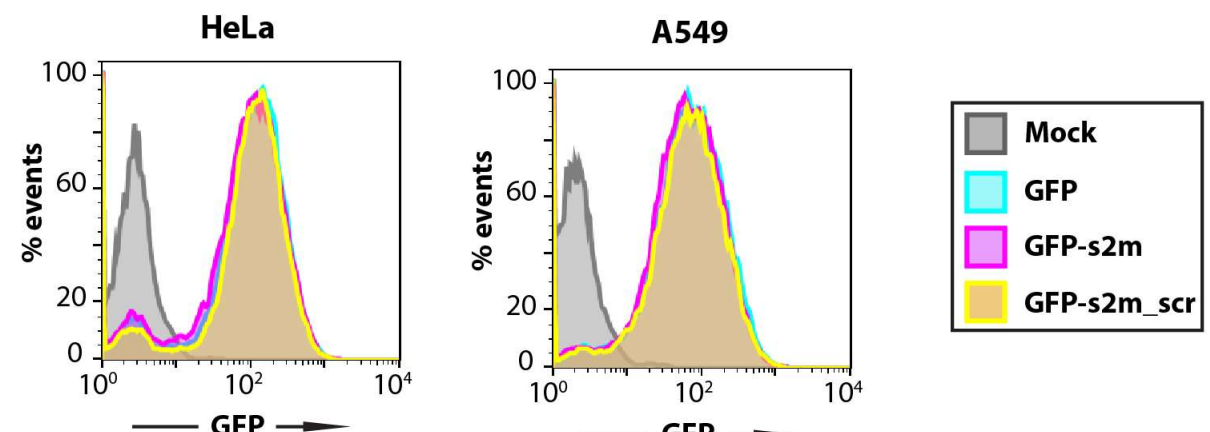

GFP

Figure S2, related to Figure 4. s2m element does not influence RNA translation in the reporter assay in human cells. (A) Schematic of the GFP reporter assay. (B) Gating and data visualisation strategy of the reporter assay data. Main cell population was identified and gated on Forward and Side Scatter using the Auto Gate tool and plotted as a histogram to visualise GFP intensity of cells. (C) HeLa and A549 cell lines containing a genomic insertion of a GFP reporter construct without additional insertion in its $3^{\prime}$ UTR (GFP), with the s2m sequence in 

made available under aCC-BY 4.0 International license.

its 3' UTR (GFP-s2m) or with a scrambled sequence insertion in its 3' UTR (GFP-s2m_scr) were analysed by flow cytometry. Data are representative of two independent experiments. 
A HeLa
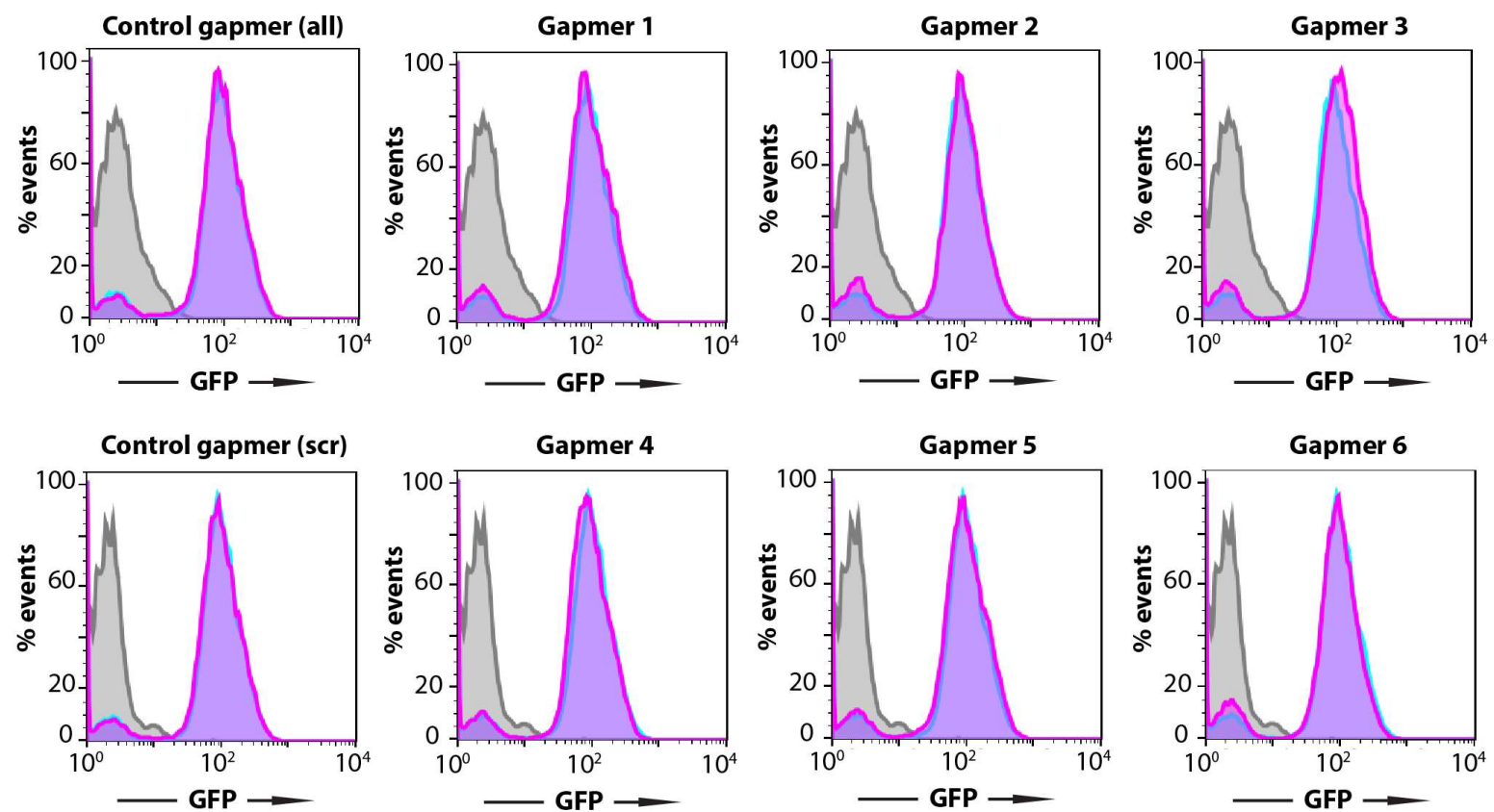

B

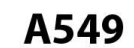

\section{Mock GFP-s2m_scr}

GFP-s2m_scr + Gapmer
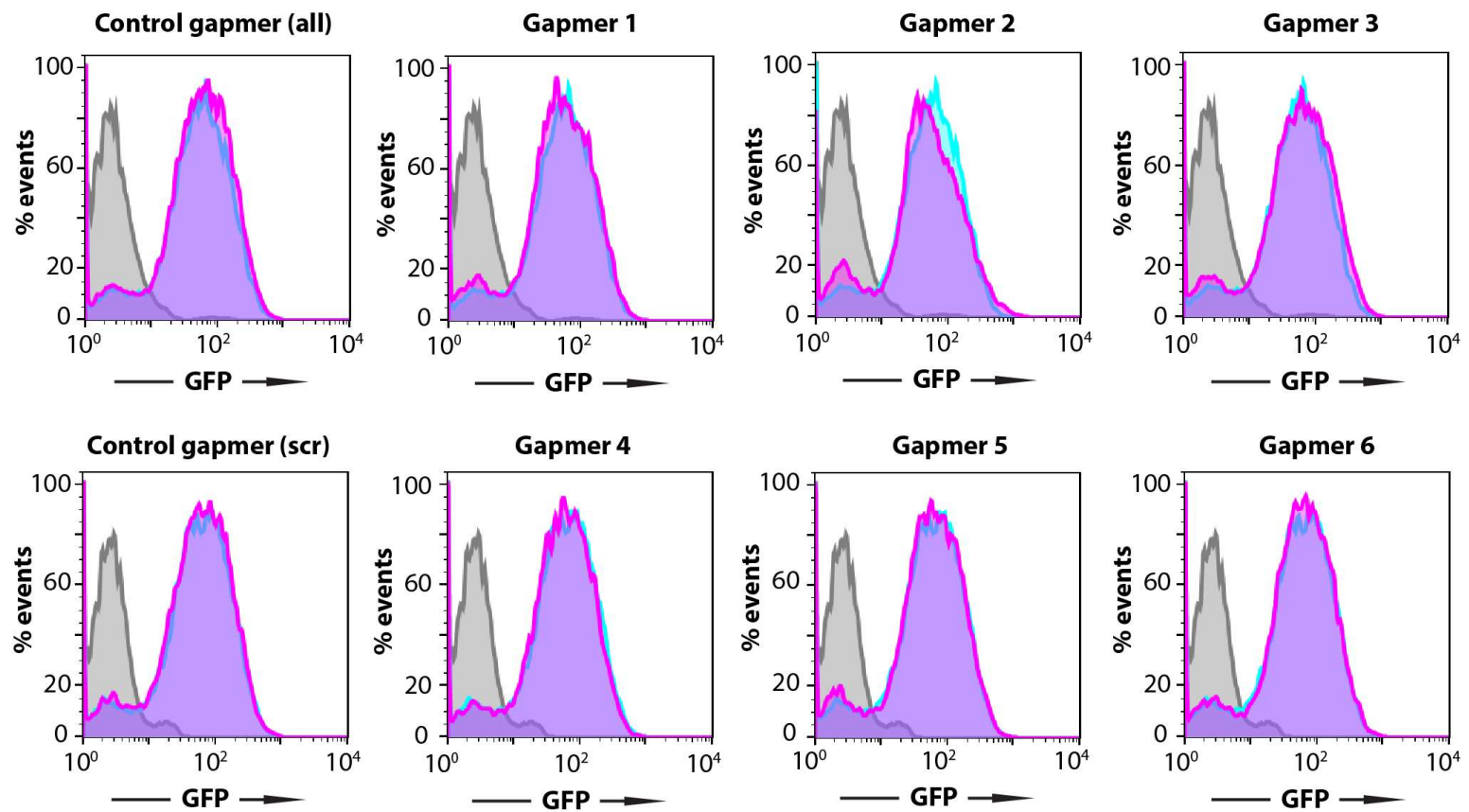

Figure S3, related to Figure 4. Gapmer silencing effect relies of sequence-specific gapmertarget interaction. HeLa (A) and A549 (B) cell lines containing a control genomic insertion of a GFP reporter construct with a scrambled sequence inserted in its 3' UTR (GFP-s2m_scr) were transfected with $20 \mathrm{nM}$ of the indicated gapmers and analysed $72 \mathrm{~h}$ post-transfection by flow cytometry. The control cell lines containing GFP reporter with a scrambled sequence insertion in the 3' UTR show no appreciable change in fluorescence upon treatment with the gapmers targeted against the $\mathrm{s} 2 \mathrm{~m}$ element. Data are representative of three independent 


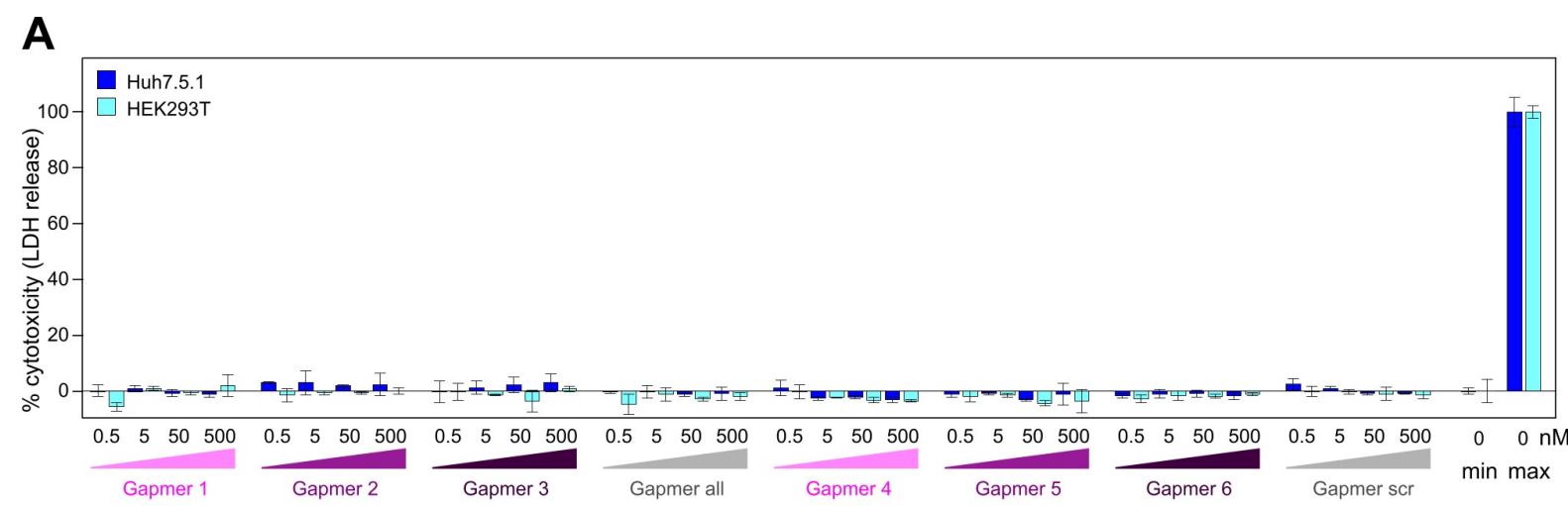

B

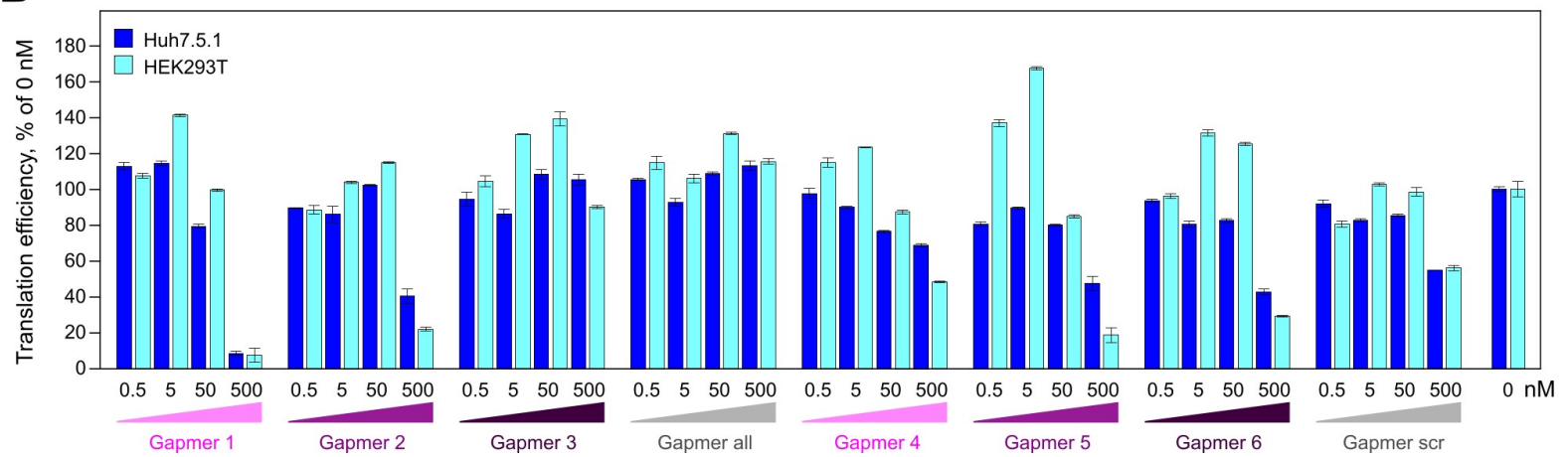

Figure S4, related to Figure 5. Testing the cytotoxic and off-target effects of gapmers. (A) Toxicity assay for gapmer-treated cells. Cells were treated with $0.5-500 \mathrm{nM}$ gapmers for $24 \mathrm{~h}$. Supernatant was used to measure cell viability, calculated as the ratio of released to total lactate dehydrogenase (LDH) activity; "max" = maximum LDH measured for fully lysed cells. (B)

974 The effect on translation measured as a readout of capped T7 RNA encoding firefly luciferase at $0.5-500 \mathrm{nM}$ gapmer concentration, normalized to untreated cells. All data are presented as mean \pm s.d.; $n=3$ biologically independent experiments. 